\title{
Budget-Constrained Sequential Auctions with Incomplete Information*
}

\author{
Carolyn Pitchik
}

17 April 2006

\begin{abstract}
I study a budget-constrained, private-valuation, sealed-bid sequential auction with two incompletely-informed, risk-neutral bidders in which the valuations and income may be non-monotonic functions of a bidder's type. Parameters permit the existence of multiple equilibrium symmetric bidding functions that differ in allocation, efficiency and revenue. The sequence of sale affects the competition for a good and therefore also affects revenue and the prices of each good in a systematic way that depends on the relationship among the valuations and incomes of bidders. The sequence of sale may affect prices and revenue even when the number of bidders is large relative to the number of goods. If a particular good, say $\alpha$, is allocated to a strong bidder independent of the sequence of sale, then auction revenue and the price of $\operatorname{good} \alpha$ is higher when good $\alpha$ is sold first.
\end{abstract}

Keywords: sequential auctions, budget constraints, efficiency, revenue, price, sequence.

JEL Classification: C7, C72, L1

* Please send correspondence to Prof. C. Pitchik, Dept. of Economics, University of Toronto, 150 St. George St., Toronto, M5S 3G7, Canada, Internet: pitchik@chass.utoronto.ca

* I thank Paul Klemperer, Preston McAfee, Martin J. Osborne, Mike Peters, Andrew Schotter, and Ralph Winter for helpful comments and discussions. I gratefully acknowledges financial support from the Social Sciences and Humanities Research Council of Canada. 
Budget-Constrained Sequential Auctions with Incomplete Information

\section{Introduction}

Much of the existing theoretical work on auctions concentrates on the allocation of a single good $^{1}$. However, in actual auctions, several heterogeneous goods are often allocated sequentially. If there is no link among the goods then one may be able to apply the single-good analysis repeatedly. However, such a link may arise if budget constraints limit a bidder's ability to bid for later goods when earlier prices deplete limited resources.

Individual bidders whose valuations derive from consumption (rather than resale) may clearly be budget-constrained. But the relevance of budget constraints extends well beyond this case. There is a theoretical literature that argues generally that the existence of agency problems implies that firms are effectively budget constrained in their investment decisions ${ }^{2}$. There is also an empirical literature that supports this idea ${ }^{3}$. Thus, theoretical and empirical foundations support the existence of budget constraints. In the context of auctions, for example, even firms that are buying to re-sell may effectively be budget-constrained if the cost of borrowing increases with the amount borrowed ${ }^{4}$ (as it is standard to assume in the finance literature) or if capital market imperfections result in budgets for projects being determined on a yearly basis, so that the firms allocate only a fixed amount of capital ${ }^{5}$ for the completion of a project. Engelbrecht-Wiggans (1987) shows that budget constraints effectively arise if a bidder is the agent of a principal.

When investments are relatively large then capital market imperfections can mitigate the ability of even a large firm to borrow funding. The historic auction of radio spectrum by the FCC in the USA is a good example of an auction in which the investments are relatively large. Cramton (1994) finds it realistic to assume that all firms in PCS (personal communicating services) auctions face budget constraints ${ }^{6}$. As he explains, bidders must raise funds before the auction starts when they do not know exactly how much they will need. Given that

\footnotetext{
1 See, for example, Maskin and Riley (1984), Myerson (1981), Harris and Raviv (1981), Riley and Samuelson (1981), Chatterjee and Samuelson (1983), Myerson and Satterthwaite (1983), Leininger, Linhart, and Radner (1986), Milgrom and Weber (1982), and Wilson (1984). For a survey of the literature, see Milgrom (1987), McAfee and McMillan (1987) and Klemperer (1999).

2 See Lewis and Sappington (1989a, 1989b), Hart and Moore (1995) and Clementi and Hopenhayn (2003).

3 See Fazzari and Athey (1987), Fazzari, Hubbard and Petersen (1988), Whited (1992), Fazzari and Petersen (1993), Love (2003) and Clementi and Hopenhay (2003) for empirical corroboration of budget constraints. 4 See Cramton (1995) for a discussion of the budget constraints faced by firms making large investments in the nationwide narrowband PCS auction held in the United States in July 1994.

5 See Hendricks and Porter (1992) for empirical evidence of capital constraints in land lease auctions.

6 As do Burguet and McAfee 2005.
} 


\section{Budget-Constrained Sequential Auctions with Incomplete Information}

fund-raising is time-consuming and costly, he states that it is reasonable to assume that firms that come to such auctions are budget-constrained. In addition, only forty per cent of narrow band PCS spectrum was for sale in the first spectrum auction held by the FCC; so that, though each spectrum auction was simultaneous, goods were allocated sequentially across auctions as well as simultaneously within an auction.

The paper analyzes a private value sequential auction with imperfect information in which bids are continuous. However, that the order of sale affects prices and revenues can be illustrated in a common value auction with complete information and discrete bids. Consider an auction in which two bidders compete (under $2^{\text {nd }}$ price sealed bid rules for which the bids are in multiples of 1's) for two goods whose values are 200 and 60 respectively. Suppose that the income of one bidder is 130 and that of the other is 60 . Note that once good 1 is sold, the income of the winner of good 1 is reduced by the price of good 1. Bidder i's equilibrium $\mathrm{bid}^{7}$ for good 2 is the minimum of i's valuation for good 2 and i's depleted income. The price of either good can be at most 60 since 60 is the income of one of the bidders. Let bidders and goods be denoted by their initial incomes and values. Bidder 130 has more than enough income to pay 60 for each good. This implies that bidder 60 is willing to pay 60 for whatever good is brought up for sale first since the value of each good is at least 60 and bidder 60 has no option to win good 2 since bidder 130 has at least 70 to bid on good 2 no matter who is allocated good 1 in equilibrium. The maximum that bidder 130 is willing to pay for good 1 depends on the order of sale.

Consider the order of sale equal to 200, 60. Bidder 130 faces a price of 60 on good 60 if bidder 60 loses good 200. Thus, if bidder 130 pays a price of $p$ for good 200 then bidder 130 's payoff is $200-p$. If instead, bidder 130 allows bidder 60 to obtain good 200 for a price of $p \leq 60$ then bidder 60 has $60-p$ to bid on good 60 . In this case bidder 130 receives a payoff of $p$. Since $200-p>p$ when $p \leq 60$, bidder 130 is willing to pay more than 60 for good 200 when it is brought up for sale first. So, when the order is 200, 60, each good is allocated to bidder 130 at a price of 60 and revenue equals 120 .

Now consider the order of sale 60, 200. Bidder 130 is no longer willing to obtain good 60 at any price less than or equal to 60 . If bidder 130 obtains good 60 at a price of $p \leq 60$, then bidder 130 also obtains good 200 at a price of 60 so that bidder 130 's payoff is $200-p$. However, if bidder 130 lets bidder 60 obtain good 60 at a price of $p \leq 60$ then bidder 130 obtains good 200 at a price of $60-p$ so that bidder 130 's payoff is $140+p$. Since

7 For the details of solutions to auctions of complete information with two budget-constrained bidders and two goods see Benoit and Krishna 2000, Pitchik and Schotter 1988, and Pitchik and Schotter 1986. 


\section{Budget-Constrained Sequential Auctions with Incomplete Information}

$140+p>200-p$ for $p>30$, bidder 130 prefers to let bidder 60 obtain good 60 if the price is $p>30$. Thus, bidder 130's best response to a bid of 60 by bidder 60 is a bid of 59. (Recall that bids are multiples of one.) Thus, when the order of sale is 60,200 , bidder 60 obtains good 60 at a price of 59, bidder 130 obtains good 200 at a price of 1 and the revenue is 60. Bidder 130 prefers to obtain good 200 at a low price under the order 60,200 than to obtain both goods at relatively high prices under the order 200,60. The prices and revenue generated by the order 200, 60 are higher than that generated by the order 60, 200 .

The order of sale affects revenue and prices whether information is perfect and bids are discrete or whether information is imperfect and bids are continuous. The intuition derives from the fact that once good 1 is sold, there is an option to win good 2. The value of the option depends on the depleted income of all bidders and on the value of the good 2 . The depleted income depends on the order of sale. The above example might lead one to believe that selling the more highly valued good first always generates the highest revenue. In fact, Benoit and Krishna (1998) show that in a complete information common value auction of two goods and three budget-constrained bidders, this is always the case. Their result extends to two goods and $n$ budget-constrained bidders since it is only the top three incomes that are relevant when analyzing the equilibria of a budget-constrained auction of two goods in a complete information common value auction with two or more bidders. However, it is easy to generate budget-constrained sequential common value auctions in which selling the most highly valued of 3 goods does not generate the highest revenue ${ }^{8}$.

A more plausible proscription for revenue maximization might exist if a good is highlyvalued enough and incomes are low enough. In this case, selling the highly valued good first maximizes revenue ${ }^{9}$. (Thus, you might want to sell a Rembrandt before selling a ten year old Honda Accord if you are selling both in a sequential auction.) What is not clear is whether there are any systematic rules that govern the relationship among the prices of a good, the revenue, and the order of sale when the valuations are similar and when the income covers the valuation of each good. If Toyota Camrys are sold in an auction that also sells Honda Accords, then does the order of sale still affect prices and revenue?

I study a budget-constrained version of the benchmark model of a private-valuation sealed-bid sequential auction of two goods in which two risk-neutral bidders are drawn from

8 One complete information example is that in which 3 bidders (with incomes of 60, 80 and 80) compete for 3 goods (with common values of 80, 60 and 100) using second price rules in which bids are multiples of one. The order of sale 80,60, 100 generates a revenue of 130 while each of the other orders generates a revenue of 120. Benoit and Krishna (1998) provide another example in which two perfectly and completely informed budget-constrained bidders compete for three goods with valuations $A \geq B \geq C$.

9 I show such a result in Section 7 for a restricted set of auctions. 


\section{Budget-Constrained Sequential Auctions with Incomplete Information}

a single population and the information is incomplete ${ }^{10}$. When information is complete, revenue is affected, in a systematic way ${ }^{11}$, by the price formation rule (i.e. the rule that specifies the price as a function of the bids). Essentially, budget constraints impose an odd sort of risk aversion and risk aversion causes revenue to depend on the price formation rule. Assuming information is incomplete does not change this. In order to isolate the pure effect of the budget-constraints on the prices of goods relative to their order of sale and the price formation rule, I restrict to a world in which the expected revenue is invariant with respect to a class of price formation rules that includes $1^{\text {st }}$ and $2^{\text {nd }}$ price rules. In this world, I find that the auction revenue depends on the sequence of sale and that the price of a good depends on its position in the sequence of sale in an intuitive way.

In the literature on auctions for one good, authors restrict the search for an equilibrium among symmetric bidding functions that increase in a bidder's type. In a budget-constrained sequential auction of two goods, I restrict attention to symmetric bidding functions but do not assume monotonicity. I find that it is possible for there to exist two symmetric equilibrium bidding functions that differ with respect to efficiency, revenue and allocation. Whether revenue is maximized or the allocation is efficient depends on the relationship between the bidding function and the valuation and income functions and not on the price rules.

Theorem 2 and its Corollary 3 can be used to compare the expected revenue and efficiency when heterogenous goods $\alpha$ and $\beta$ say, are sold in the order $\alpha, \beta$ to that when they are sold in the order $\beta, \alpha$. Revenue is maximized when the bidding function is ordinally equivalent to the income function. The allocation is efficient when the bidding function is ordinally equivalent to the difference in valuation functions. In particular, if the valuation and income functions are increasing then revenue is maximized and the allocation is efficient when the good whose valuation increases more rapidly in a bidder's type is sold first. Thus, even when there are only two goods, selling the highest valued good first need not generate the highest revenue. In particular, if one is auctioning the contents of a household, then selling a wall painting by an unknown artist (whose value may be highly variable) before the used ride-on lawn mower (whose value may be high but publicly known) maximizes revenue.

Theorem 4 compares the prices of good 1 with that of good 2. If the goods are identical for each type of bidder and the bidding function is ordinally equivalent to the income function, then the expected price of a good is higher the later it is sold. Though the price of identical

\footnotetext{
10Benoit and Krishna (2000) consider budget constrained buyers with complete information. Che and Gale (1993) consider budget constrained buyers in one-good auctions. Pitchik and Schotter (1986), Pitchik and Schotter (1988) and Pitchik (1989) considers budget constrained buyers with incomplete information.

11See Benoit and Krishna (2000), Pitchik and Schotter (1988), and Pitchik and Schotter (1986).
} 


\section{Budget-Constrained Sequential Auctions with Incomplete Information}

goods increases in the order of sale, each bidder expects to pay a constant price for any good that is won (Theorem 6) so that there is no room for arbitrage.

The price formation rule may affect the price of a good even if it does not affect revenue (Theorem 7). In addition, auction revenue and allocation may differ across symmetric equilibrium bidding functions (Theorems 8 and 9).

When I restrict attention to $1^{\text {st }}$ and $2^{\text {nd }}$ price rules I obtain the following results. Theorem 10 finds that the expected price of good 1 is higher under $2^{\text {nd }}$ price rules than under $1^{\text {st }}$ price rules. Theorems 11 and 12 compare the price of good $\alpha$ when heterogeneous goods $\alpha$ and $\beta$ are sold in the order $\alpha, \beta$ to the price of good $\alpha$ when goods $\alpha$ and $\beta$ are sold in the order $\beta, \alpha$. Whether the price of good $\alpha$ is higher when it is sold first than when it is sold second depends on how competition for the good is affected by its position in the order of sale. Competition for a good depends on the bidding function as well as the price formation rules. Theorem 11 echoes the results of Theorem 4. Under either first or $2^{\text {nd }}$ price rules, if the bidding function is ordinally equivalent to the income function, then good 1 is always sold to the bidder with the higher income so that there can be no disadvantage in obtaining the good 1. Otherwise, the more advantaged bidder could always mimic the less advantaged one if there was a gain to doing so. As a consequence, under either price formation rule, identical goods fetch different prices if they are sold in sequence. The expected price of a good is higher the later it is sold. By contrast, the results of Theorem 12 show that the results may depend on the price formation rule. If income is constant and the equilibrium bidding function is ordinally equivalent to the difference in valuations of the goods then the allocation is efficient and independent of the sequence of sale. This allows for variation in how cautious bidders are in bidding for good 1. $2^{\text {nd }}$ price rules allow bidders to bid up the price with greater impunity. Under $2^{\text {nd }}$ price rules the price of a good is higher when it is sold first rather than second. The bidder who loses good 1 may bid up its price in order to obtain good 2 for a lower price. Under $1^{\text {st }}$ price rules, the price of a good is higher when it is sold second. The bidder who loses good 1 fears bidding up the price due to the possibility of obtaining the good at too high a price.

The fact that the sequence of sale affects both the prices and revenue means that the interests of a seller who may wish to maximize the price of a good may conflict with those of an auctioneer who may wish to maximize long run auction revenue. A change in the form of the auction may change the number of bidders who are attracted by the mechanism, a consideration that does not enter my model ${ }^{12}$.

\footnotetext{
$\overline{12 \text { McAfee (1993) and Peters and Severinov }}$ (1993) study competition among auctioneers.
} 


\section{Budget-Constrained Sequential Auctions with Incomplete Information}

Theorems 4, 11, and 12 imply that the law of one price does not hold for similar goods in a budget-constrained sequential auction. If the goods $\alpha$ and $\beta$ are identical and the bidding function is ordinally equivalent to the income function, then the expected price is higher the later it is sold. If the goods $\alpha$ and $\beta$ are similar (with a common mean) but the value of one good is even slightly more variable than the other and income is constant across types of bidders, then the expected price is higher the earlier it is sold under $2^{\text {nd }}$ price rules; under $1^{\text {st }}$ price rules, it is higher the later it is sold.

In an auction of multiple identical goods, some assumption is required in addition to those of the standard multi-good auction model to obtain the result that the price of an object depends on its position in the order of sale ${ }^{13}$. Weber (1983) shows that in a standard private valuation sequential auction in which bidders are risk neutral and goods are not linked in any way, prices of identical objects do not depend on their position in the sequence in which they are sold when each bidder wants only one unit of the good. McAfee and Vincent (1993) show that in the absence of risk neutrality, decreasing prices for identical goods in a standard auction requires non-decreasing absolute risk aversion. Black and De Meza (1993) show that, under $2^{\text {nd }}$ price rules, expected prices increase with respect521to the order of sale when bidders value additional purchases.

Ashenfelter (1989) and Ashenfelter and Genesove (1993) provide empirical evidence that ex ante identical goods fetch prices that depend on their position in the order of sale. Ashenfelter (1989) finds that in about half of the cases the price of a good is about twice as likely to be lower than to be higher than the price of an identical good sold earlier, while in the remaining cases the price does not change over time. In addition, Genesove (1993) suggests that credit-rationing of new and used car dealers may explain the empirical evidence that the sequential position of sale affects the price of a car in wholesale used car auctions. When goods are similar, a corollary of my results offers an explanation of the evidence in terms of the existence of a link between the goods, specifically a budget constraint that causes the willingness and ability to pay for a good to depend not only on some absolute valuation of the good but also on the opportunity cost of paying for good 1 when there is a subsequent possibility of buying good 2. As the income constraints change over the course of a sequential auction, the intensity of competition for later goods changes. A change in the order of sale affects the opportunity cost of winning a good.

Black and De Meza (1993) obtain declining expected prices in a sequential auction of two identical goods under $2^{\text {nd }}$ price rules when each of two bidders has access to a buyer's 13See Black and De Meza (1993), Weber (1983), and McAfee and Vincent (1993). 


\section{Budget-Constrained Sequential Auctions with Incomplete Information}

option $^{14}$ and marginal utility is declining. When there are more than two bidders, the result also requires some restrictions on the distribution of values. Bernhardt and Scoones (1993) and Gale and Hausch (1992) obtain declining expected prices in a sequential auction of two goods under $2^{\text {nd }}$ price rules when bidders are risk neutral. Two assumptions that drive Bernhardt and Scoones' result are that no bidder can evaluate good 2 until the first has been allocated and that no bidder is allowed to obtain more than one good. In my model the goods may be heterogeneous and the auction form is not restricted to $2^{\text {nd }}$ price rules. The price of a good depends on the order of sale and the interaction among the valuations and income of bidder types. Each bidder obtains no more than one good in equilibrium, but the bidders are not constrained ex ante from obtaining both goods independent of the prices and bids; further, bidders know their valuations of both goods at the beginning of the auction. In addition, the valuations and income may be non-monotonic. Other work ${ }^{15}$ deals with the allocation of multiple goods to multiple bidders, but none of which I am aware specifically analyzes the allocation of multiple goods auctioned sequentially to a set of incompletelyinformed, budget-constrained bidders with private valuations. The aim of the paper is to understand how the relationship between auction revenue, allocation, prices and the order of sale may vary within the context of a single model as a function of the relationship among the parameters of the model and the price formation rule.

Previous models in the literature use varying assumptions to drive the relationship between the price of a good and its order of sale so that the various results are hard to compare within the context of a single model. When I restrict to similar goods in my model, whether the price increases or decreases with its position in the order of sale depends, in a systematic way, on the relationship between the bidding function and the valuation and income functions as well as on the price formation rules. The relationship among valuations and income as well as the price formation rule govern the relationship between the order of sale and both the price of a good and the revenue of the auction.

I present the model in Section 2. I relate the price of a good to its position of sale in Section 3 and to the price formation rule in Section 4. I consider the existence of multiple equilibrium bidding functions in Section 5. I restrict to $1^{\text {st }}$ and $2^{\text {nd }}$ price rules in Section 6. I consider the robustness of the results in Section 7.

\footnotetext{
14In a sequential auction with identical goods a buyer's option enables the bidder who wins the first unit to purchase as many units as are available at the price of the first unit.

${ }_{15}$ See Benoit and Krishna (2000), Bernhardt and Scoones (1993), Bulow and Klemperer (2002), EngelbrechtWiggans and Weber (1979), Engelbrecht-Wiggans and Menezes (1993), Gale and Hausch (1992), Gale and Stegeman (2001), Krishna (1990,1993), McAfee and Vincent (1993), Menezes (1993), Ortega-Reichert (1968), Palfrey (1980), Pitchik and Schotter (1986,1987), von der Fehr (1994), Weber (1983) and Swinkels (1989).
} 


\section{Budget-Constrained Sequential Auctions with Incomplete Information}

\section{The Model}

There is a single population from which bidders 1 and 2 are drawn. Two heterogeneous goods, $\alpha$ and $\beta$, are to be sold sequentially. The first good sold (good 1) may be either $\alpha$ or $\beta$. A bidder's privately known type is independently and randomly drawn according to the publicly known distribution $H$ from the interval [0,1]; I assume that $H$ is atomless, continuously differentiable, and increasing on its support $[0,1]$. The income and valuations of a bidder of type $t$ for good $\gamma=\alpha, \beta$ are denoted $I(t)$ and $v_{\gamma}(t), \gamma=\alpha, \beta$ respectively. I assume that $v_{\gamma}, \gamma=\alpha, \beta$, and $I$ are continuously differentiable functions on $[0,1]$.

I also assume that either $v_{1}^{\prime}-v_{2}^{\prime}+I^{\prime} \neq 0$ on a set of positive Lebesgue measure or that $v_{1}^{\prime}-v_{2}^{\prime} \neq 0$ on a set of positive Lebesgue measure. (Note that although each individual's income and valuations may be perfectly correlated in the case that valuations and income increase in $t$, the income and valuations of one individual are not correlated with those of any other individual. I do not assume monotonicity of the valuation or income functions.)

In order that the valuations are meaningful I assume that for each type, income is at least equal to each valuation; in order that the budget constraint be effective I assume that, for each type, income is at most the sum of the valuations. Precisely,

$$
v_{\gamma}(t) \leq I(t) \leq v_{\alpha}(t)+v_{\beta}(t) \text { for } \gamma=1,2 \text { and } t \in[0,1]
$$

where the first inequality is strict for $t \in(0,1)$.

This assumption has two implications. (1) Individual $t$ is willing and able to pay up to $I(t)$ in exchange for both goods. I call the maximum amount that an individual is willing and able to pay for a good, the individual's de facto valuation of the good. Thus, income is an individual's de facto valuation of holding both goods. (2) A bidder's de facto valuation of good 2 is the minimum of $v_{2}$ and any income remaining after any payment for good 1 is made. A bidder's de facto valuation of good 1 takes into account the fact that the higher the price paid by the winner of good 1 the lower the winner's de facto valuation of good 2 . Thus, losing good 1 at a higher price may enable a bidder to obtain good 2 at a lower price.

A bidder of type $t$ is constrained not to spend more than $I(t)$ ( $t$ 's income) in the auction. All units (i.e. bids, budgets and valuations) are restricted to be non-negative. Ties are broken by the flip of a fair coin. The above is common knowledge among the bidders.

The sealed bid sequential auction works as follows. Two bidders are selected at random from the population. In the first stage, good 1 , which may be $\alpha$ or $\beta$, is brought up for sale. Each participant submits a bid for good 1 that lies in $[0, I(t)]$. The bidder who submits the 


\section{Budget-Constrained Sequential Auctions with Incomplete Information}

higher bid obtains good 1. The price paid for the good depends on the price formation rule in effect. After good 1 is sold, the winner's budget is reduced by the price paid for good 1 and the winning bid is revealed. Bidders then bid on good $2(\{\alpha, \beta\}=\{1,2\})$.

In the second stage of the game, the de facto valuation for good 2 of a bidder of type $t$ is the minimum of $t$ 's initial valuation and t's remaining income. I assume that once good 1 is allocated, the price paid for good 1 along with the income of the winner of good 1 is public knowledge. In this case, it is reasonable to assume that the equilibrium outcome in this second stage is that in which the bidder with the higher de facto valuation obtains the good at the lower de facto valuation, so that the price of good 2 is the lower de facto valuation. Replacing the second stage of the game by the equilibrium payoffs in this standard equilibrium outcome we obtain a one-stage Bayesian ${ }^{16}$ game $G$ that depends on the distribution of valuations and resources for each population of bidders. This Bayesian game $G$ is the game that I study. The strategy set of a bidder of type $t$ in $G$ is $[0, I(t)]$, the set of feasible bids on good 1. The rules of $G$ are the auction rules that allocate good 1 given bids; I restrict attention to rules under which the individual who makes the higher bid obtains good 1 and pays a price that is a non-decreasing function of the bids. (This includes but is not limited to $1^{\text {st }}$ and $2^{\text {nd }}$ price formation rules.) I consider a symmetric Bayesian equilibrium of $G$; that is, I look for a function $B:[0,1] \rightarrow \Re$ that assigns a bid to each type with the property that $(B, B)$ is a Nash equilibrium of $G$.

It is known that the price formation rule can affect the revenue of an auction when information is complete and so also when information is incomplete. I want to isolate the effect of the sequence of sale on the price of a good and therefore restrict to parameters for which revenue is independent of the price formation rule. In order to avoid looking at

special cases, and in order to consider auctions in which the revenue is independent of the price formation rule, I assume that, in equilibrium, a bidder's income is large enough to cover expenses and that no bidder is allocated both goods in equilibrium. Moreover, since no individual is allocated both goods in equilibrium, the price of good 2 is the de facto valuation for good 2 of the winner of good 1.

\section{The Sequence of Sale Affects Revenue and Prices}

In a standard private value auction of only one good, the valuation of the good (which coincides with a bidder's de facto valuation) increases in a bidder's type and the maximum

16See Fudenberg and Tirole (1991). 


\section{Budget-Constrained Sequential Auctions with Incomplete Information}

private valuation indicates the maximum revenue that an auction can generate. A bidding function that increases in a bidder's type maximizes the revenue generated and allocates the good in an efficient manner to the bidder who values the good more highly. The literature typically restricts the search to symmetric equilibrium bidding functions that increase in a bidder's type. In budget-constrained sequential auctions, the willingness to pay for good 1 depends on the valuations for both goods and on income. In addition, a bidding function that increases in this willingness to pay may not maximize revenue or allocate goods efficiently. I first discuss a bidder's de facto valuation for good 1.

In a budget-constrained sequential auction, individual t's de facto valuation of good 1 depends on the type of t's opponent. As shown in the example computed in the introduction, losing good 1 at a high price may enable a bidder to obtain good 2 at a low price. This may be preferred to winning both goods at high prices. Let $V(t, s)$ denote the de facto valuation for good 1 of a bidder of type $t$ who faces another bidder of type $s$. If a bidder of type $t$ faces a bidder of type $s$, then it must be the case that bidder $t$ is willing to pay up to

$$
\frac{v_{1}(t)-v_{2}(t)+I(s)}{2}
$$

for good 1 , since, at such a price, whether the individual wins or loses good 1 , the payoff of individual $t$ is

$$
\frac{v_{1}(t)+v_{2}(t)-I(s)}{2}
$$

Thus, the de facto valuation of bidder $t$ who faces bidder $s$ equals

$$
V(t, s)=\frac{v_{1}(t)-v_{2}(t)+I(s)}{2}
$$

Define the critical value $v(t)=V(t, t)$ to be the de facto valuation for good 1 of a bidder of type $t$ who faces another bidder of type $t$. In the auction literature for one good, the critical value is synonymous with the bidder's valuation for the good.

Suppose that $f$ and $g$ are real-valued functions on a domain $S$. I say that $f$ is ordinally equivalent (denoted ORD-equivalent) to $g$ on $S$ whenever the set of indifference curves and "better than" sets are common for $f$ and $g$ on $S$. In particular, any strictly monotonically increasing function is ORD-equivalent to any other strictly monotonically increasing function. I say that $f$ is ordinally reversed (denoted ORDR-equivalent) to $g$ whenever there is one common set of indifference curves but the "better than" set of one function is the "worse than" set of the other function. In particular, any strictly monotonically increasing function is ORDR-equivalent to any strictly monotonically decreasing function. 


\section{Budget-Constrained Sequential Auctions with Incomplete Information}

In a standard auction, the literature restricts to a symmetric equilibrium bidding function that is ORD-equivalent to the valuation function. I consider symmetric equilibrium bidding functions that are ORD-equivalent to the critical value. However, unlike in the private valuation auction literature for one good, a bidding function that is ORD-equivalent to the critical value does not necessarily allocate the goods and income efficiently. It turns out (Theorem 2) that a symmetric equilibrium bidding function that is ORD-equivalent to $v_{1}-v_{2}$ allocates the goods and income efficiently. Thus, I also consider symmetric equilibrium bidding functions that are ORD-equivalent to $v_{1}-v_{2}$ so as to obtain an efficient allocation of the goods and income. There exist parameters for which there exists two non-equivalent equilibrium bidding functions that differ in their allocation of the goods.

In order to show that the set of parameters that satisfy the assumptions is not empty, I offer a condition that satisfies the assumptions. One condition that would allow one to avoid looking at special cases, and to consider auctions in which the revenue is independent of the price formation rule, is that, for all $t \in[0,1]$

$$
\max _{s} V(t, s) \leq I(t) \leq \min _{s} V(t, s)+\min _{s} v_{2}(s)
$$

This condition satisfies the two assumptions since no bidder is willing to pay more than the highest critical value and no equilibrium price of good 1 can be lower than the lowest critical value. The second inequality of (2) says that, in equilibrium, any income remaining to the winner of good 1 must be less than or equal to the lowest valuation of good 2. But this implies that the loser of good 1 must obtain good 2 in equilibrium. Moreover, the income of the winner of good 1 is depleted to below the winner's valuation of good 2 . It follows that the price of good 2 is the depleted income of the winner of good 1. But then, in equilibrium

$$
\text { Revenue }=\text { income of the winner of good } 1
$$

It is immediate that a bidding function that is ORD-equivalent to the income function maximizes auction revenue.

In the theorem below I consider budget-constrained sequential auctions in which income and valuations satisfy all assumptions (this may happen for example if the parameters satisfy (1) and (2)) and whose price formation rules satisfy the following conditions.

(S1) Bidders are treated anonymously (prices do not depend on the identity of bidders).

(S2) A good is sold to the higher bidder at a price that does not decrease in the bids.

(S3) Good 2 is sold to the bidder with the current higher de facto valuation at a price equal to the current lower de facto valuation. 


\section{Budget-Constrained Sequential Auctions with Incomplete Information}

(S4) There is a common symmetric equilibrium bidding strategy $B$ for good 1.

Whether revenue is maximized or the allocation is efficient depends on the equivalence between the bidding function and the functions $v_{1}-v_{2}, I$ and $v_{1}-v_{2}+I$. In a standard auction of one good, the efficient allocation is that in which the good is allocated to the bidder with the highest valuation. This is because, without budget constraints, a bidder is always willing and able to bid up to the bidder's valuation. An allocation in a budgetconstrained auction is efficient if there are no Pareto improving trades but the willingness and ability of an individual to pay for a good depends not only on the bidder's valuation for the good but also on the bidder's remaining income. In any auction allocation of goods and money let type $t_{\theta}$ denote the type allocated good $\theta$ and income $R_{\theta}$ for $\theta \in(\alpha, \beta)$.

Criterion 1 The allocation $\left(\left(t_{\alpha}, R_{\alpha}\right),\left(t_{\beta}, R_{\beta}\right)\right)$ is efficient if and only if

$$
\begin{aligned}
& v_{\alpha}\left(t_{\beta}\right) \leq v_{\alpha}\left(t_{\alpha}\right) \text { or } R_{\beta} \leq v_{\alpha}\left(t_{\alpha}\right) \\
& v_{\beta}\left(t_{\alpha}\right) \leq v_{\beta}\left(t_{\beta}\right) \text { or } R_{\alpha} \leq v_{\beta}\left(t_{\beta}\right)
\end{aligned}
$$

and

$$
\begin{array}{ll}
\text { either } v_{\alpha}\left(t_{\alpha}\right)-v_{\beta}\left(t_{\alpha}\right) \geq v_{\alpha}\left(t_{\beta}\right)-v_{\beta}\left(t_{\beta}\right) \\
\text { or } \quad R_{\beta} \leq v_{\alpha}\left(t_{\alpha}\right)-v_{\beta}\left(t_{\alpha}\right) \\
\quad R_{\alpha} \leq v_{\beta}\left(t_{\beta}\right)-v_{\alpha}\left(t_{\beta}\right)
\end{array}
$$

We next explore when an allocation is efficient and revenue is maximized. All proofs not in the text are in the Appendix.

Theorem 2 In any budget-constrained sequential auction, the expected revenue is independent of the price formation rules and depends only on the shape of the equilibrium bidding function $B$. Whenever $B(t)$ is ORD-equivalent to $I(t)$, expected revenue is maximized. Moreover, such a revenue-maximizing sequential auction reaps more revenue than any auction in which both goods are bundled and allocated simultaneously to one of the bidders. Whenever $B(t)$ is ORD-equivalent to $v_{1}(t)-v_{2}(t)$, the allocation of goods and money is efficient.

The Corollary follows immediately from Theorem 2.

Corollary 3 If $B, v_{i}(t)-v_{j}(t)$ and $I$ are ORD-equivalent, then revenue is maximized and the goods are allocated efficiently when good $i$ is sold first.

Bernard and Scoones [1993] consider a $2^{\text {nd }}$ price sequential auction of two stochastically independently valued goods (denoted by A and B). Bidders are restricted to bidding on one good only and do not know their own valuation of good 2 until after good 1 has been 


\section{Budget-Constrained Sequential Auctions with Incomplete Information}

allocated. They find that the seller's revenues are greater when object A is auctioned first if the distribution of valuations for A has more dispersed order statistics than that of the distribution of valuations for B. By contrast, the above theorem and corollary hold for any auction form under consideration for which the income constraints are binding. In particular, the proof here does not require the explicit calculation of equilibrium bidding functions, the bidders know their valuations ex ante, and the bidders may bid on more than one good. Thus, if there is a book value for one good that is highly valued but the value for the other good is relatively low but highly variable then revenue is maximized when the good with the book value is sold last. This predicts that, in estate auctions, heavy equipment (for example, ride on lawn mowers) will be sold later than an item whose value may depend more heavily on taste (for example, used bedspreads).

Note that I do not consider auctions in which all surplus is always extracted from the winner of good 2. One such case is that in which good 1 is allocated via an auction mechanism and good 2 is awarded to the loser of good 1 at the loser's valuation (which can be achieved if the bidding function is monotonic and the auctioneer knows the bidding function and therefore knows the valuations for good 2 once good 1 is allocated). In this case, it can be shown that the expected revenue is independent of the auction mechanism under which good 1 is awarded; the maximal expected revenue is the expected value of $\min \left\{v_{1}\left(t_{1}\right)+\right.$ $\left.v_{2}\left(t_{1}\right), v_{1}\left(t_{2}\right)+v_{2}\left(t_{2}\right)\right\}$. However, this method of allocation requires a lot of information on the part of the auctioneer. Competition among auctioneers mitigates against its use and increases the surplus available to bidders.

The next result shows that the law of one price need not hold for identical goods. We see that, in any auction under consideration, the expected prices of identical goods depend on the sequence of sale. Income constraints are enough to imply that the expected price of identical units of a good increases the later it is sold. By contrast, Black and De Meza [1993] analyze a model in which two units of a good are sold sequentially in a $2^{\text {nd }}$ price sealed bid auction to $n$ bidders whose incomes are not constrained. In their model, a consumer's valuation of a unit depends on how many units the consumer has already bought. Under some assumptions on valuations ${ }^{17}$, the expected price of the second unit sold is higher than that of the first. The result below is not restricted to $2^{\text {nd }}$ price rules.

Theorem 4 If the equilibrium bidding function $B(t)$ is ORD-equivalent to $v_{1}(t)-v_{2}(t)+I(t)$ and $I(t)$, then the expected price of good 1 is less than that of good 2 whenever $v_{2}\left(w_{1}\right)-$

17The valuation $b$ of the first unit bought by a consumer is drawn independently from a common distribution. The valuation of the second unit bought is $k b$ where $k$ is fixed and common to each bidder. 


\section{Budget-Constrained Sequential Auctions with Incomplete Information}

$v_{1}\left(w_{1}\right) \geq 0$ where $w_{1}$ denotes the expected type for which

$$
v_{1}\left(w_{1}\right)-v_{2}\left(w_{1}\right)+I\left(w_{1}\right)=\exp \max \left(v_{1}\left(t_{1}\right)-v_{2}\left(t_{1}\right)+I\left(t_{1}\right), v_{1}\left(t_{2}\right)-v_{2}\left(t_{2}\right)+I\left(t_{2}\right)\right)
$$

It follows immediately that whenever each bidder considers the two goods to be identical, the expected price of the good 1 sold is higher than that of good 1.

Corollary 5 If $v_{\alpha}(t)=v_{\beta}(t)$ for all t and the equilibrium bidding function is ORD-equivalent to $I$, then the expected price of good 2 sold is higher than that of good 1.

In particular, the expected prices differ if the goods are identical across bidder types. I now explore opportunities for arbitrage in this case.

Theorem 6 If $v_{\alpha}(t)=v_{\beta}(t)=v(t)$ for all $t$ and the equilibrium bidding function is ORDequivalent to $I$, then the expected price that any one bidder expects to pay in the auction is constant across bidders.

Theorems 4 and 6 state that when $v_{\alpha}(t)=v_{\beta}(t)$ for all $t$ and the bidding function is ORD-

equivalent to $I$, the expected price of good 1 is less than that of good 2 even though the expected price that any one bidder expects to pay in the auction is constant across bidders. To see how this result is possible, let $p^{*}$ be the common expected price that a bidder expects to pay in the auction. Since good 1 is allocated to the bidder with the higher bid and good 2 is allocated to the bidder with the lower bid, the bidder whose type is associated with the highest bid obtains good 1 for sure at a price of $p^{*}$, while the bidder whose type is associated with the lowest bid obtains good 2 for sure at a price of $p^{*}$. Since the price paid for a good is increasing in the bids, $p^{*}$ is the highest price paid for good 1 and the lowest price paid for good 2. A bidder whose type is associated with a bid between the highest and lowest bids sometimes obtains good 1 for a price lower than $p^{*}$ and sometimes obtains good 2 for a price higher than $p^{*}$ but on average obtains a good for a price of $p^{*}$.Thus, the price that any single bidder expects to pay in the auction is constant across bidders even though the expected price of good 1 is lower than that of good 2. A violation of the law of one price does not imply opportunities for arbitrage.

\section{The Expected Price of a Good Depends on the Price Formation Rule}

Theorem 2 shows that the revenue can be affected by the sequence of sale when income varies with type. It follows that, if income varies, then the sequence of sale can also affect 


\section{Budget-Constrained Sequential Auctions with Incomplete Information}

the prices of the goods. However, as shown below, the price formation rule may affects the prices even in the case that income is constant across types. In addition, the price formation rule may affect the way in which the price of a good depends on the sequence of sale.

Let $B$ be an equilibrium bidding function. Since $(B, B)$ is an equilibrium of $G$, the "truthful" strategy profile in which each type $t$ chooses $t$ is an equilibrium of the associated game $\bar{G}(B)$ in which each bidder's strategy set is the set $[0,1]$ of types and the payoff of type $t$ when $s$ is announced is that which type $t$ obtains in $G$ when type $t$ bids $B(s)$. I study equilibria of $\bar{G}(B)$ for any continuous bidding function $B$ that is not constant over any interval. Riley and Samuelson (1981) study only continuous bidding functions that increase in $t$ since the valuation of the single good is continuous and increases in $t$. They find that the equilibrium price (and therefore revenue) is independent of the price formation rule. By contrast, even though the expected revenue is independent of the price formation rule, the equilibrium price of good 1 varies with the rule.

Theorem 7 The equilibrium price of good 1 depends on the price formation rules.

Thus, even though the world is restricted to be one in which the expected revenue is independent of the price formation rule, the expected prices do vary with the rules. Che and Gale [1993] show that in a budget-constrained auction of one good, the expected price of the single good (which is equivalent to revenue in this case) is higher under $1^{\text {st }}$ price rules than under $2^{\text {nd }}$ price rules. In the auctions that we consider, revenue is constant across price rules but the price of each good varies across rules.

\section{Relationship between Bidding Function and Exoge- nous Functions}

In this section, we analyze the relationship between the shape of the equilibrium bidding function and either $v_{1}-v_{2}+I$ or $v_{1}-v_{2}$. We first show that the existence of a non-monotonic equilibrium bidding function is tied to the existence of a non-monotonic $v_{1}-v_{2}$.

Theorem 8 If there exists $S_{1} \subset[0,1]$ and $S_{2} \subset[0,1] \backslash S_{1}$ and a function $\widehat{x}: S_{1} \longrightarrow S_{2}$ for which the equilibrium bidding function $B$ satisfies $B(t)=B(\widehat{x}(t))$ for $t \in S_{1}$, then the difference in the value functions satisfies $v_{1}(t)-v_{2}(t)=v_{1}(\widehat{x}(t))-v_{2}(\widehat{x}(t))$ for $t \in S_{1}$.

We say that a function is S-monotonic on an interval $T$ if, for $t \in T$, the indifference curve through $t$ is the singleton $\{t\}$. We now show that the existence of an S-monotonic equilibrium bidding function on an interval $T$ is tied to the existence of a monotonic $v_{1}-v_{2}+I$. 


\section{Budget-Constrained Sequential Auctions with Incomplete Information}

Theorem 9 Suppose that $D_{12} P(t, s)=D_{21} P(s, t)=0$ for all $s, t$ and either one of $D_{1} P(t, s)$ and $D_{2} P(s, t)$ equals zero or $D_{2} P(t, s)=\gamma D_{1} P(s, t)$ for $\gamma>0$. If an equilibrium bidding function $B$ is $S$-monotonic on an interval $T$, then $\operatorname{sign}\left(B^{\prime}\right)=\operatorname{sign}\left(v_{1}-v_{2}+I\right)$ on $T$.

We note that when $P$ is not a member of the class of price rules assumed by Theorem 9 , then $B$ may or may not be ORD-equivalent to $v_{1}-v_{2}+I$ when $B$ is monotonic ${ }^{18}$. Theorems 8 and 9 indicate the possible existence of multiple bidding functions that differ with respect to allocation, revenue and efficiency ${ }^{19}$.

\section{$6 \quad 1^{\text {st }}$ and $2^{\text {nd }}$ Price Rules}

I now restrict attention to $1^{\text {st }}$ and $2^{\text {nd }}$ price formation rules. Theorem 10) generalizes a theoretical and experimental complete information result in Pitchik and Schotter (1988).

Theorem 10 If the equilibrium bidding function under $1^{\text {st }}$ price rules is ORD-equivalent to the equilibrium bidding function under $2^{\text {nd }}$ price rules, then the expected price of good 1 is higher under $2^{\text {nd }}$ price rules than under $1^{\text {st }}$ price rules.

Intuitively, under $1^{\text {st }}$ price rules, a bidder is worried about being allocated good 1 at a relatively high price and so makes a relatively conservative bid. Under $2^{\text {nd }}$ price rules, a bidder is worried about not winning the good at a relatively low price.

Theorem 4 implies that when the goods are identical, the expected price of a good is higher the later it is sold under general price rules. Theorems 11 and 12 below compare the price of a good when it is sold first to the price of the good when it is sold second under $1^{\text {st }}$ and $2^{\text {nd }}$ price rules. There are two cases to consider.

When income is an index of an individual's ability to use the good profitably, then we expect that $v_{1}-v_{2}+I$ to be ORD-equivalent to $I$ independent of the order of sale since, then, the value of a good changes less rapidly than the value of income. Denote by $B_{\theta \gamma}$ the equilibrium bidding function when the order of sale is $(\theta, \gamma)$ for $\{\theta, \gamma\}=\{\alpha, \beta\}$.

Theorem 11 If $v_{\alpha}-v_{\beta}+I, v_{\beta}-v_{\alpha}+I, I$, are ORD-equivalent to the equilibrium bidding functions $B_{\alpha, \beta}$ and $B_{\beta, \alpha}$ then the expected revenue is independent of the sequence of sale and the expected price of a good is higher, the later it is sold.

18If $P(s, t)=P(t, s)=\sqrt{B(s) B(t)}$, then the assumptions of Theorem 9 are violated. Equation (4) is solved by the increasing $B(t)=(t+1)^{2}$ if either $v_{1}(t)-v_{2}(t)+I(t)=3 t^{2}+6 t+\frac{1}{2}$ (is increasing) and $H(t)=t$ or if $v_{1}(t)-v_{2}(t)+I(t)=\frac{10}{3} t^{2}+8 t-\frac{8}{3} t^{1 / 2}+2$ (is non-monotonic) and $H(t)=t^{1 / 2}$.

19Two bidding functions $\bar{B}$ and $\widehat{B}$ exist if $v_{1}-v_{2}+I$ and $I$ increase on $[0,1]$ but $v_{1}-v_{2}$ increases on [0,a], is concave on $[a, 1]$ such that $v_{1}(a)-v_{2}(a)=v_{1}(1)-v_{2}(1) . \bar{B}$, that is S-increasing on $[0,1]$, allocates good one to the bidder with the higher income and maximizes revenue. $\widehat{B}$, that is S-increasing on $[0, a]$ and is ORD-equivalent to $v_{1}-v_{2}$ on $[a, 1]$, allocates the goods efficiently but does not maximize revenue. 


\section{Budget-Constrained Sequential Auctions with Incomplete Information}

Thus, if income varies widely relative to the value of either good (as might happen when the goods are economy cars) then the expected price of the good is higher the later it is sold.

When the valuation for one good is highly variable because of vagaries of taste or because of the existence of imperfect markets and the random nature of private information, then we expect $v_{\alpha}-v_{\beta}$ to be ORDR-equivalent to $v_{\beta}-v_{\alpha}$. We would like to compare the price of goods as a function of the sequence but in order to do so we need to keep revenue constant. In the case that the shape of the critical value function depends on the sequence in which the goods are sold, the expected revenue is independent of the sequence only if the income is independent of type. In this case, either sequence maximizes revenue. If income is constant across types and $v_{\alpha}-v_{\beta}+I$ is ORDR-equivalent to $v_{\beta}-v_{\alpha}+I$, then the expected prices of the goods depend on the sequence and on the price formation rules as stated next.

Theorem 12 Suppose that $v_{1}-v_{2}+I$ is ORD-equivalent to the bidding function under either order but that $v_{\alpha}-v_{\beta}+I$ is ORDR-equivalent to $v_{\beta}-v_{\alpha}+I$ and $I(t)=I$ is constant. (1) Under $1^{\text {st }}$ price rules the expected price of a good is higher the later it is sold. (2) Under $2^{\text {nd }}$ price rules the expected price of a good is higher the earlier it is sold.

Clearly whether the price of a good increases or decreases with its order in the sequence of sale depends on the price formation rules in this case ${ }^{20}$. The reason the results in Theorem 12 are so different from those of Theorems 4 and 11 is as follows. As the variation in the differences in valuation for each good are essentially dwarfed by that of income in Theorems 4 and 11, income plays the following role in determining the allocation of each good. The individual with the higher income obtains good 1 under either sequence and under any price formation rule. Thus, the results do not depend on the price formation rule and the allocation varies with the sequence. However, in Theorem 12, the variation in the valuation of good $\alpha$ say dwarfs that of good $\beta$ and income combined so that both the valuation and position (whether first or second) of good $\alpha$ play a role in determining the price of each good. In this case, under any price formation rule and under any sequence, the individual who values good $\alpha$ more highly obtains good $\alpha$.

Now suppose that the value of one good, $\alpha$ say, varies with a bidder's type while the income and the value of the other good, say $\beta$, is independent of the bidder's type. Further suppose that the values share a common mean. In this case, Theorem 12 implies that the price of similar goods decreases with its position in the order of sale as the auction proceeds under $2^{\text {nd }}$ price rules. Under $2^{\text {nd }}$ price rules, a bidder is able to bid up the price of good 1 in order to obtain good 2 at a lower price than otherwise.

$\overline{20 \text { generalizing theoretical and experimental }}$ complete information results in Pitchik and Schotter (1988). 


\section{Budget-Constrained Sequential Auctions with Incomplete Information}

\section{Robustness}

I consider the robustness of the results with respect to $2^{\text {nd }}$ price rules in this section. Previously, I have assumed that bidders draw their types from a common pool and that the number of bidders and goods equal two. I have also assumed that each valuation is less than income and that no individual obtains both goods in equilibrium. My aim in this section is to show that revenue and prices can be affected by the sequence in which the goods are sold even when these assumptions are relaxed. In particular, I consider two possibilities below. In the first, the number of bidders is larger than the number of goods and the income is less than the valuations. In the second, one bidder may obtain both goods in equilibrium.

I first provide an example in which the order of sale in a sequential auction of two goods can affect the revenue of an auction and the price of a good even in the presence of many bidders who each have a common income. Consider an auction of two goods $\alpha$ and $\beta$ to $n>2$ bidders. Suppose that $I(t)=I$ and $v_{\alpha}(t)>(n-1)\left(v_{\beta}(t)-I\right)+I>v_{\beta}(t)-I>I>0$ for $t \in[0,1]$ so that each individual has constant income that is less than the valuation of either good and each individual highly values good $\alpha$ relative to good $\beta$ and income. Note that, since each bidder is endowed with a common fixed income that is less than the valuation of either good, no bidder obtains more than one good in equilibrium. I want to compare the price of each good if the order of sale is $\alpha \beta$ to that when the order of sale is $\beta \alpha$. If the order of sale is $\alpha \beta$ then each individual's equilibrium bidding function for good $\alpha$ is $^{21} B(t)=I$. Thus, the expected equilibrium price of $\operatorname{good} \alpha$ is $I$. Since $n>2$ there are still at least two individuals with an income of $I$ who compete for good $\beta$. So, when the goods are sold in the order $\alpha \beta$, the price of $\operatorname{good} \alpha$ is $I$; that of $\operatorname{good} \beta$ is $I$ since $n>2$. If instead, the goods are sold in the order $\beta \alpha$ then I claim that the expected price of $\beta$ is less than $I$. The reason is as follows. Suppose that the expected price of $\beta$ is $I$. In this case, at least two individuals bid $I$. Let $m \geq 2$ be the number of individuals who bid $I$. The payoff to each who bids $I$ is $\left(v_{\beta}(t)-I\right) / m+[(m-1) / m]\left(v_{\alpha}(t)-I\right) /(n-1)$ while the payoff to anyone who bids just less than $I$ is $\left(v_{\alpha}(t)-I\right) /(n-1)$. By assumption $v_{\alpha}(t)-I>(n-1)\left(v_{\beta}(t)-I\right)$, so that it cannot be that $m \geq 2$ bidders bid $I$ in equilibrium. Thus, the equilibrium price of $\beta$ must be less than $I$. It follows that when the goods are sold in the order $\beta \alpha$ the expected equilibrium price of $\beta$ is less than $I$ as claimed. Thus, revenue is highest when $\alpha$ is sold first and the price of $\beta$ increases with its position in the order of sale. The reason is that when $\beta$ is sold second, there are always at least two individuals who are willing and able to pay $I$ for $\beta$ so

$\overline{21 \mathrm{~A} \text { bid of } I \text { results in the payoff } v_{\alpha}(t) / n+v_{\beta}}(t)(n-1) / n(n-1)-I$. A bid less than $I$ results in $v_{\beta}(t) /(n-1)-I$. 


\section{Budget-Constrained Sequential Auctions with Incomplete Information}

that competition is intense when $\beta$ is sold second; when $\beta$ is sold first, competition is not as intense since each bidder wants to have income to bid on good $\alpha$.

The above illustrates that the revenue and prices of goods may depend on the sequence in which the goods are sold even when there are many bidders and only two goods. Under the above assumptions, revenue is maximized when the more valuable good is sold first.

I now analyse the model when there are asymmetries among the bidders as well as changes to the assumptions on income relative to valuations so that a bidder may obtain both goods in equilibrium. Let's assume that the valuations of the two goods are fixed such that $v_{\alpha}(t)=A, v_{\beta}(t)=B<A$. Suppose that there are two pools of bidders. Bidder one is richer than bidder two, although neither is rich relative to the value of good $\alpha$. Specifically, let's assume that $I_{1}(t) \in\left[c_{1}, d_{1}\right]$ and that $I_{2}(t)=I$ where $A>d_{1}>c_{1}>2 I>B>I$ so that bidder 1 has enough income to buy both goods since bidder 2 is relatively and absolutely poor. If the goods are auctioned in the order $\alpha, \beta$ then each bidder is willing to pay at least $I$ for $\alpha$ so that bidder one obtains good $\alpha$ at a price of $I$ in equilibrium. Once good $\alpha$ is allocated, each bidder is willing to pay at least $I$ for $\operatorname{good} \beta$. Since bidder one has more than double the income of bidder two and since good $\alpha$ is relatively highly valued, bidder one obtains both goods in equilibrium when the order of sale is $\alpha \beta$. The equilibrium price of each good equals $I$ and the equilibrium revenue is $2 I$. However, now suppose that the goods are sold in the order $\beta, \alpha$. In this case, bidder one is not willing to pay $I$ for good $\beta$. The payoff to bidder one is $A-(I-p)$ if bidder one gives up good $\beta$ to bidder two at a price of $p$. If instead, bidder one wins good $\beta$ at a price of $p$ then bidder one receives $B-p+A-I$. It follows that the most that bidder one is willing to pay for $\operatorname{good} \beta$ is $B / 2<I$. Bidder two is willing to pay up to $I$ for good $\beta$ since otherwise, bidder two receives nothing. In the equilibrium allocation when the goods are sold in the order $\beta \alpha$, bidder two obtains good $\beta$ and bidder one obtains good $\alpha$. The equilibrium price of $\beta$ is $B / 2$ and that of $\alpha$ is $I-B / 2$. The equilibrium revenue is $I$. In summary, the revenue is higher when $\alpha$ (the more highly valued good) is sold first; the price of good $\alpha$ (the good that is allocated to the rich bidder independent of its order of sale) is higher when $\alpha$ is sold first; the price of good $\beta$ (the good that is allocated to the rich bidder only when it is sold second) is higher when $\beta$ is sold second. That revenue is higher when $\alpha$ is sold first is consistent with the implications of Theorem 2 in which the revenue is higher when good 1 is sold to the rich bidder. Under the assumptions of Theorem 12, $\alpha$ is allocated to the rich bidder, independent of the order of sale and the price of $\alpha$ is higher the earlier it is sold under $2^{\text {nd }}$ price rules. In our example, $\alpha$ is allocated to the rich bidder independent of the order of sale and the price of $\alpha$ is higher 


\section{Budget-Constrained Sequential Auctions with Incomplete Information}

the earlier it is sold. That the price of good $\alpha$ is higher when sold first in our example is therefore consistent with Theorem 12. Under the assumptions of Theorem 11 the price of a good is higher the later it is sold when the competition for the good is higher the later it is sold. In our example, $\beta$ is allocated to the rich bidder only when it is sold second so that competition for $\beta$ is higher when it is sold second. That the price of $\operatorname{good} \beta$ is higher when sold second is consistent with Theorem 11.

Thus, even when one bidder is relatively rich, revenue and price may depend on the order of sale. If there is one good that is highly valued by all and there is a clearly strong bidder then revenue is higher when the more valuable good is sold first; the more valuable good is allocated to the stronger bidder independent of its position of sale and its price is higher when it is sold first; the less valuable good is allocated to the stronger bidder only if it sold second and its price is higher when it is sold second. Whether the price of a good increases or decreases with its position in the order of sale depends on how the order of sale affects the competition for the good.

The price of a good is affected by the order of sale. How it is affected depends on the valuations. In one case, the price is higher when a good is sold earlier. In another case, the price is higher when a good is sold later. It depends on whether, in equilibrium, good 1 goes to the stronger bidder independent of which good is sold first or whether a designated good goes to the stronger bidder. When good 1 goes to the stronger bidder independent of the order of sale, then there is no disadvantage in obtaining good 1 because, if there were, the stronger bidder would just mimic the weaker bidder. In this case, the price of a good must increase with its position in the order of sale. When a designated good goes to the higher bidder, then the competition for the good is higher when it is sold first and so price decreases with its position in the order of sale.

\section{Conclusion}

In the presence of budget constraints there may exist two symmetric equilibrium bidding functions that differ with respect to allocation, prices and revenue. Prices depend on the price formation rules. In addition, even in the absence of arbitrage possibilities, identical goods may fetch different prices. The sequence of sale affects the expected revenue through the allocation of the goods. Whenever the winner of good 1 is the bidder with the higher income, expected revenue is maximized. Under $1^{\text {st }}$ and $2^{\text {nd }}$ price rules, whenever, independent of the sequence, the winner of good 1 is the bidder with the higher income, the expected 


\section{Budget-Constrained Sequential Auctions with Incomplete Information}

price of a good is no lower the later it is sold. Intuitively, if good 1 is always sold to the stronger bidder, then there can be no disadvantage in winning good 1. This happens when the goods are similar enough and income is relatively variable. By contrast, if, independent of the sequence, the stronger bidder is allocated a designated good (that may be good 1 or good 2), the expected price of a good decreases under $2^{\text {nd }}$ price rules and increases under $1^{\text {st }}$ price rules. Intuitively, under $2^{\text {nd }}$ price rules, there is an incentive for the loser of good 1 to bid up its price, depleting the winner's income, in order to obtain good 2 at a lower price. Thus, when the allocation of the goods is independent of the sequence and $2 n d$ price rules prevail, the expected price of a good declines with its position in the order of sale. Under $1^{\text {st }}$ price rules, a higher bid of the loser does not affect the price of good 1 and may adversely affect the payoff of the loser so that bids are more conservative.

Basically, the price of a good is higher whenever competition for the good is higher. If bidders are drawn from populations that differ according to income, then goods that are always allocated to the richer bidder fetch a higher price when sold first. Goods that are sold to the richer bidder only when sold second fetch a higher price when sold second.

Other links between the goods can have the same effect as do budget-constraints. For example, if firms with limited plant capacities bid on projects let by the government, the results of letting any given contract will depend on the available capacity of firms in the industry. The results should not be qualitatively different in this case.

\section{Appendix}

Proof of Theorem 2: By (R), expected revenue equals the expected income of the winner of good 1. If $B(t)$ is ORD-equivalent to $I(t)$ under any price formation rule then good 1 is allocated to the bidder with the higher income so that, by $(\mathrm{R})$, the expected revenue is the expected value of the higher income. Thus, the expected revenue is independent of the price formation rules and depends only on the shape of the equilibrium bidding function.

We now compare revenue in the revenue-maximizing sequential auction to that in an auction in which both goods are sold simultaneously. When both goods are sold simultaneously to one of the bidders, rather than sequentially, an individual t's de facto valuation of holding both goods is $I(t)$ by assumption (1). Thus, the auction in which both goods are sold simultaneously is equivalent to an auction in which one good is sold whose value to individual $t$ is $I(t)$. The result follows since no auction of a single good can yield an expected revenue equal to the expected value of the highest valuation (Riley and Samuelson [1981]). 


\section{Budget-Constrained Sequential Auctions with Incomplete Information}

In the case that the bidding function is ORD-equivalent to $v_{1}-v_{2}$, the individual who obtains good 1 (say type $t_{1}$ ) has the higher $v_{1}-v_{2}$ while the individual who obtains good 2 (say type $t_{2}$ ) has the lower $v_{1}-v_{2}$. By assumption, in equilibrium, the remaining income $R_{1}$ of the individual $t_{1}$ is less than $v_{2}\left(t_{2}\right)$, the valuation for good 2 of individual $t_{2}$. Thus, if the bidding function $B$ is ORD-equivalent to $v_{1}-v_{2}$, then the allocation is efficient.

Proof of Theorem 4: The de facto valuation of good 1 for a bidder of type $t$ who faces a bidder of type $s$ is $V(t, s)=\left(v_{1}(t)-v_{2}(t)+I(s)\right) / 2$. Since $B$ is ORD-equivalent to $v_{1}-v_{2}+I$ and $I$, the average price that a bidder of type $t$ expects to pay for good 1 is strictly less than bidder t's critical value $v(t)=\left(v_{1}(t)-v_{2}(t)+I(t)\right) / 2$. In this case the expected price of good 1 must be strictly less than the critical value of the expected winner. Thus, the expected price of good 1 must be strictly less than

$$
\frac{v_{1}\left(w_{1}\right)-v_{2}\left(w_{1}\right)+I\left(w_{1}\right)}{2}
$$

However, by $(\mathrm{R})$, the expected revenue is $I\left(w_{1}\right)$. Thus, the expected price of good 2 must be strictly greater than

$$
\frac{v_{2}\left(w_{1}\right)-v_{1}\left(w_{1}\right)+I\left(w_{1}\right)}{2}
$$

and therefore the difference between the expected price of good 2 and that of good 1 is strictly greater than $v_{2}\left(w_{1}\right)-v_{1}\left(w_{1}\right)$ as required.

Proof of Theorem 6: If the other bidder uses the equilibrium strategy $B(t)$, let $\Delta(x)$ be the probability that a bidder of type $t$ who pretends to be type $x$ wins good 2 and let $\widetilde{P}(x)$ be the expected payment made by such a bidder. The expected payoff $\Pi(t, x)$ of such a bidder equals the expected benefit minus the expected payment

$$
\Pi(t, x)=v_{1}(t)(1-\Delta(x))+v_{2}(t)(\Delta(x))-\widetilde{P}(x)
$$

Let $D_{i}^{\prime}$ denote the partial derivative operator with respect to the $i$ th variable. In equilibrium, $D_{2}^{\prime} \Pi(t, x)$ equals 0 when $x=t$ so that

$$
-\left(v_{1}(t)-v_{2}(t) \Delta^{\prime}(t)=\widetilde{P}^{\prime}(t)\right.
$$

Since $v_{1}(t)=v_{2}(t),(3)$ implies $\widetilde{P}^{\prime}(t)=0$ for all $t$ as required.

In order to prove the next Theorem, we need to develop further the expected payment made by an individual of type $t$ who pretends to be of type $x$. Let $P^{*}(x)$ denote the expected price that an individual (who claims to be of type $x$ ) pays for good 1 and $P_{*}(x)$ denote the expected price that an individual (who claims to be of type $x$ ) pays for good 2 . Thus, 


\section{Budget-Constrained Sequential Auctions with Incomplete Information}

$\widetilde{P}(t, x)=P^{*}(x)+P_{*}(x)$. Let $P(x, z)$ denote the price that an individual who claims to be of type $x$ pays for good 1 if the other individual claims to be of type $z$. It is also necessary to define the circumstances under which an individual might win good 2. Recall that the de facto valuation of good 2 of a bidder of type $t$ is the minimum of $t$ 's valuation for good 2 and any income remaining to $t$ from the auction of good 1 . The individual with the higher de facto valuation obtains good 2 at the lower de facto valuation. There are two ways in which individual $t$ may obtain good 2. Either individual $t$ wins good 1 and has enough income remaining to win good 2 as well; or, individual $t$ loses good 1 and $t$ 's valuation of good 2 is higher than the remaining income of $t$ 's opponent.

Let $\sigma_{1}(t, x)$ be the set of opponents who lose good 1. Of these, some may also lose good 2. Denote this latter set by $\sigma_{12}(t, x)$. Let $\sigma_{2}(t, x)$ denote the set of opponents who lose only good 2. Thus, if $s \in \sigma_{12}(t, x)$ then individual $t$ obtains good 1 at the price $P(x, s)$ and obtains good 2 at the price $v_{2}(s)$; if $s \in \sigma_{1}(t, x)$, then individual $t$ obtains good 1 at the price $P(x, s)$ and may or may not obtain good 2; if instead $s \in \sigma_{2}(t, x)$ then individual $t$ loses good 1 and obtains good 2 at the price $\min \left\{v_{2}(s), I(s)-P(s, x)\right\}$. In equilibrium, the expected payoff must be maximized when $x=t$. By assumption, no bidder wins both goods in equilibrium so that, in equilibrium, $\sigma_{12}(t, t)=\varnothing\left(\right.$ which implies that $\left.\sigma_{1}(t, t)+\sigma_{2}(t, t)=1\right)$ and $v_{2}(s)>I(s)-P(s, t)$ for $s \in \sigma_{2}(t, t)$. If $s(x)$ is an upper end point of an interval in $\sigma_{1}(t, x)$ that varies with $x$ then $s(x)$ is a lower end point of an interval in $\sigma_{2}(t, x)$ so that the derivative (evaluated at $x=t$ ) of $\int_{\sigma_{1}(t, x)} H^{\prime}(s) d s$ with respect to $x$ equals the the negative of the derivative (evaluated at $x=t$ ) of $\int_{\sigma_{2}(t, x)} H^{\prime}(s) d s$ with respect to $x$. Thus, in equilibrium,

$$
\widetilde{P}(t)=P^{*}(t)+P_{*}(t)=\int_{\sigma_{1}(t, t)} P(t, s) H^{\prime}(s) d s+\int_{\sigma_{2}(t, t)}(I(s)-P(s, t)) H^{\prime}(s) d s
$$

Proof of Theorem \%: In equilibrium, $P(s, t)=P(t, t)$ for all endpoints $s$ of intervals in $\sigma_{2}(t, t)$ that depend on $t$. Since, in equilibrium,

$\widetilde{P}^{\prime}(t)=\int_{\sigma_{1}(t, t)} D_{1}^{\prime} P(t, s) H^{\prime}(s) d s-\int_{\sigma_{2}(t, t)} D_{2}^{\prime} P(s, t) H^{\prime}(s) d s-2 P(t, t) \Delta^{\prime}(t)+\frac{d}{d t} \int_{\sigma_{2}(t, t)} I(s) H^{\prime}(s) d s$

(3) implies that $2 P(t, t) \Delta^{\prime}(t)$

$=\left(v_{1}(t)-v_{2}(t)\right) \Delta^{\prime}(t)+\frac{d}{d t} \int_{\sigma_{2}(t, t)} I(s) H^{\prime}(s) d s-\int_{\sigma_{2}(t, t)} D_{2} P(s, t) H^{\prime}(s) d s+\int_{\sigma_{1}(t, t)} D_{1} P(t, s) H^{\prime}(s) d s$

So, since

$$
P^{* \prime}(x)=\int_{\sigma_{1}(t, t)} D_{1}^{\prime} P(t, s) H^{\prime}(s) d s-P(t, t) \Delta^{\prime}(t)
$$




\section{Budget-Constrained Sequential Auctions with Incomplete Information}

we can substitute for $P(t, t) \Delta^{\prime}(t)$ from (4) to obtain

$$
P^{* \prime}(x)=\frac{-\left(v_{1}(t)-v_{2}(t)\right) \Delta^{\prime}(t)-\delta^{\prime}(t)+\int_{\sigma_{2}(t, t)} D_{2} P(s, t) H^{\prime}(s) d s+\int_{\sigma_{1}(t, t)} D_{1} P(t, s) H^{\prime}(s) d s}{2}
$$

The left-hand side of (5) is the expected price of good one and the right-hand side of (5) depends on the price formation rule ${ }^{22}$. The result follows.

Proof of Theorem 8: Equation (4) implies that, for $t \in S_{1}$

$$
\begin{aligned}
& \int_{\sigma_{2}(t, t)} D_{2} P(s, t) H^{\prime}(s) d s-\int_{\sigma_{1}(t, t)} D_{1} P(t, s) H^{\prime}(s) d s+2 P(t, t) \frac{d}{d t} \int_{\sigma_{2}(t, t)} H^{\prime}(s) d s \\
= & \left(v_{1}(t)-v_{2}(t)\right) \frac{d}{d t} \int_{\sigma_{2}(t, t)} H^{\prime}(s) d s+\frac{d}{d t} \int_{\sigma_{2}(t, t)} I(s) H^{\prime}(s) d s
\end{aligned}
$$

and for $t \in S_{2}$

$$
\begin{aligned}
& \int_{\sigma_{2}(t, t)} D_{2} P(s, t) H^{\prime}(s) d s-\int_{\sigma_{1}(t, t)} D_{1} P(t, s) H^{\prime}(s) d s+2 P(t, t) \frac{d}{d t} \int_{\sigma_{2}(t, t)} H^{\prime}(s) d s \\
= & \left(v_{1}(t)-v_{2}(t)\right) \frac{d}{d t} \int_{\sigma_{2}(t, t)} H^{\prime}(s) d s+\frac{d}{d t} \int_{\sigma_{2}(t, t)} I(s) H^{\prime}(s) d s
\end{aligned}
$$

If instead of $t$ varying in $S_{2}$, we have $t$ varying in $S_{1}$ and $\widehat{x}(t)$ varying in $S_{2}$, we can rewrite (7) for $t \in S_{1}$, as

$$
\begin{aligned}
& \int_{\sigma_{2}(\widehat{x}(t), \widehat{x}(t))} D_{2} P(s, \widehat{x}(t)) H^{\prime}(s) d s-\int_{\sigma_{1}(\widehat{x}(t), \widehat{x}(t))} D_{1} P(\widehat{x}(t), s) H^{\prime}(s) d s \\
& +2 P(\widehat{x}(t), \widehat{x}(t)) \frac{d}{d t} \mid t=\widehat{x}(t) \\
= & \left(v_{1}(\widehat{x}(t))-v_{2}(\widehat{x}(t))\right) \frac{d}{d t} H_{\mid t=\widehat{x}(t)} \int_{\sigma_{2}(t, t)} H^{\prime}(s) d s
\end{aligned}
$$

If we then multiply both side of (8) above by $\widehat{x}^{\prime}(t)$ we obtain that, for $t \in S_{1}$,

$$
\begin{aligned}
& \int_{\sigma_{2}(\widehat{x}(t), \widehat{x}(t))} D_{2} P(s, \widehat{x}(t)) \widehat{x}^{\prime}(t) H^{\prime}(s) d s-\int_{\sigma_{1}(\widehat{x}(t), \widehat{x}(t))} D_{1} P(\widehat{x}(t), s) \widehat{x}^{\prime}(t) H^{\prime}(s) d s \\
& +2 P(\widehat{x}(t), \widehat{x}(t)) \widehat{x}^{\prime}(t) \frac{d}{d t} \mid t=\widehat{x}(t) \\
= & \left(v_{1}(\widehat{x}(t))-v_{2}(\widehat{x}(t))\right) \widehat{x}^{\prime}(t) \frac{d}{d t} H_{\mid t=\widehat{x}(t)} \int_{\sigma_{2}(t, t)} H^{\prime}(s) d s
\end{aligned}
$$

22The analog of equation (5) in the standard one good auction is $P^{* \prime}(t)=v(t) H^{\prime}(t)$ which is independent of the price formation rules. 


\section{Budget-Constrained Sequential Auctions with Incomplete Information}

However, by definition of $\widehat{x}(t), \sigma_{2}(t, t)=\sigma_{2}(\widehat{x}(t), \widehat{x}(t)), \sigma_{1}(t, t)=\sigma_{1}(\widehat{x}(t), \widehat{x}(t)), P(s, t)=$ $P(s, \widehat{x}(t)), D_{2} P(s, t)=D_{2} P(s, \widehat{x}(t)) \widehat{x}^{\prime}(t), P(t, s)=P(\widehat{x}(t), s), D_{1} P(t, s)=D_{2} P(\widehat{x}(t), s) \widehat{x}^{\prime}(t)$, $P(t, t)=P(\widehat{x}(t), \widehat{x}(t))$, and

$$
\begin{aligned}
\frac{d}{d t} \int_{\sigma_{2}(t, t)} H^{\prime}(s) d s & =\left.\widehat{x}^{\prime}(t) \frac{d}{d t}\right|_{t=\widehat{x}(t)} \int_{\sigma_{2}(t, t)} H^{\prime}(s) d s \\
\frac{d}{d t} \int_{\sigma_{2}(t, t)} I(s) H^{\prime}(s) d s & =\left.\widehat{x}^{\prime}(t) \frac{d}{d t}\right|_{t=\widehat{x}(t)} \int_{\sigma_{2}(t, t)} I(s) H^{\prime}(s) d s
\end{aligned}
$$

so equation (10), for $t \in S_{1}$, is equivalent to

$$
\begin{aligned}
& \int_{\sigma_{2}(t, t)} D_{2} P(s, t) H^{\prime}(s) d s-\int_{\sigma_{1}(t, t)} D_{1} P(t, s) H^{\prime}(s) d s+2 P(t, t) \frac{d}{d t} \int_{\sigma_{2}(t, t)} H^{\prime}(s) d s \\
= & \left(v_{1}(\widehat{x}(t))-v_{2}(\widehat{x}(t))\right) \frac{d}{d t} \int_{\sigma_{2}(t, t)} H^{\prime}(s) d s+\frac{d}{d t} \int_{\sigma_{2}(t, t)} I(s) H^{\prime}(s) d s
\end{aligned}
$$

Thus, (6) and (11) must hold for $t \in S_{1}$ which implies the result.

Proof of Theorem 9: If $B$ is S-increasing on $T$ then $\sigma_{2}(t, t)=(t, 1)$ and $\sigma_{1}(t, t)=(0, t)$ so that, since $D_{12} P\left(t_{1}, t_{2}\right)=D_{21} P\left(t_{1}, t_{2}\right)=0$, (4) implies that

$$
\begin{aligned}
& D_{2} P(t, t)(1-H(t))-D_{1} P(t, t) H(t)-2 P(t, t) H^{\prime}(t) \\
= & -\left(v_{1}(t)-v_{2}(t)+I(t)\right) H^{\prime}(t) \text { for } t \in T
\end{aligned}
$$

In the case that one of $D_{1} P(t, s)$ or $D_{2} P(s, t)$ equals zero, then, since $D_{1} P(t, t)+D_{2} P(t, t)=$ $D P(t, t),(12)$ implies that either

$$
D P(t, t)(1-H(t))-2 P(t, t) H^{\prime}(t)=-\left(v_{1}(t)-v_{2}(t)+I(t)\right) H^{\prime}(t)
$$

or

$$
D P(t, t) H(t)+2 P(t, t) H^{\prime}(t)=\left(v_{1}(t)-v_{2}(t)+I(t)\right) H^{\prime}(t)
$$

so that either

$$
P(t, t)(1-H(t))^{2}=\int_{1}^{t}\left(v_{1}(s)-v_{2}(s)+I(s)\right) \frac{d(1-H(s))^{2}}{2}
$$

implies

$$
P(t, t)=\frac{v_{1}(t)-v_{2}(t)+I(t)}{2}-\frac{\int_{1}^{t} \frac{(1-H(s))^{2}}{2}\left(v_{1}^{\prime}(s)-v_{2}^{\prime}(s)+I^{\prime}(s)\right) d s}{(1-H(t))^{2}}
$$

and

$$
D P(t, t)=\frac{2 H^{\prime}(t) \int_{t}^{1} \frac{(1-H(s))^{2}}{2}\left(v_{1}^{\prime}(s)-v_{2}^{\prime}(s)+I^{\prime}(s)\right) d s}{(1-H(t))^{3}}
$$




\section{Budget-Constrained Sequential Auctions with Incomplete Information}

or

$$
P(t, t)(H(t))^{2}=\int_{0}^{t}\left(v_{1}(s)-v_{2}(s)+I(s)\right) \frac{d\left((H(s))^{2}\right)}{2} d s
$$

implies

$$
P(t, t)=\frac{\left(v_{1}(t)-v_{2}(t)+I(t)\right)}{2}-\frac{\int_{0}^{t} \frac{(H(s))^{2}}{2}\left(v_{1}^{\prime}(s)-v_{2}^{\prime}(s)+I^{\prime}(s)\right) d s}{(H(t))^{2}}
$$

and

$$
D P(t, t)=\frac{\int_{0}^{t} \frac{(H(s))^{2}}{2}\left(v_{1}^{\prime}(s)-v_{2}^{\prime}(s)+I^{\prime}(s)\right) d s}{(H(t))^{3}}
$$

Thus, when one of $D_{1} P(t, s)$ or $D_{2} P(s, t)$ equals zero, the sign of $D P$ equals that of $v_{1}^{\prime}-v_{2}^{\prime}+I^{\prime}$. However, since $P(t, t)$ is ORD-equivalent to $B(t)$, and since $B$ is S-increasing on $T$, this implies that $v_{1}-v_{2}+I$ is increasing on $T$.

In the case that $D_{2} P(t, s)=\gamma D_{1} P(s, t)$ for $\gamma>0, D_{1} P(t, t)+D_{2} P(t, t)=D P(t, t),(12)$ implies that

$$
D P(t, t)\left(\frac{\gamma}{1+\gamma}-H(t)\right)-2 P(t, t) H^{\prime}(t)=-\left(v_{1}(t)-v_{2}(t)+I(t)\right) H^{\prime}(t)
$$

so that

$$
P(t, t)\left(\frac{\gamma}{1+\gamma}-H(t)\right)^{2}=\int_{H^{-1}\left(\frac{\gamma}{1+\gamma}\right)}^{t}\left(v_{1}(s)-v_{2}(s)+I(s)\right) \frac{d\left(\frac{\gamma}{1+\gamma}-H(t)\right)^{2}}{2}
$$

implies

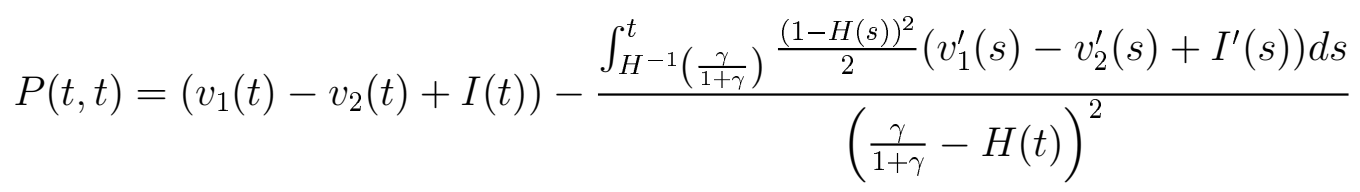

which implies

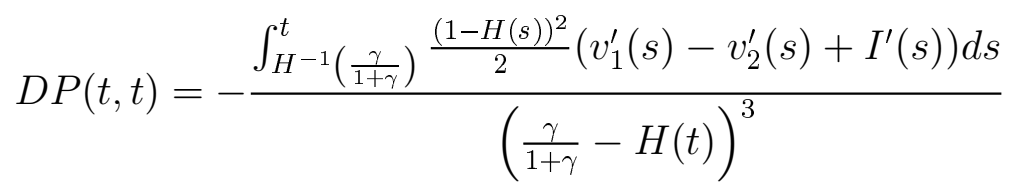

so that again to $v_{1}-v_{2}+I$ is increasing on $T$. Analogous arguments show that the results remain when $B$ is $\mathrm{S}$-decreasing on $T$.

The following lemmas are used to prove Theorems 10, 11, and 12. 


\section{Budget-Constrained Sequential Auctions with Incomplete Information}

Lemma 13 Let $W:[0,1] \longrightarrow[0,1]$ be onto and continuous. Let $J$ be the union of intervals over which the cover of $W$ is strictly monotonic on $J$. Let $W^{-1}(0)=c, W^{-1}(1)=d$ where $c<d$ or $d<c$ are the endpoints of J. Let

$$
\begin{aligned}
& F(t)=W(t) \ln W(t)-\frac{(2 W(t)-1)^{2}}{4} \\
& G(t)=2(1-W(t))^{2} \ln (1-W(t))-\frac{(2 W(t)-1)^{2}}{2}
\end{aligned}
$$

Then

$$
F(t) \leq-\frac{1}{4}, G(t) \geq-\frac{1}{2}
$$

If $L$ is ORD-equivalent to $W$, then

$$
\begin{aligned}
\int_{(c, d) \cap J} L^{\prime}(t) F(t) d t & \leq-\frac{1}{4} \int_{(c, d) \cap J} L^{\prime}(t) d t \\
\int_{(c, d) \cap J} L^{\prime}(t) G(t) d t & \geq-\frac{1}{2} \int_{(c, d) \cap J} L^{\prime}(t) d t
\end{aligned}
$$

If $L$ is ORDR-equivalent to $W$ and $W^{\prime}>0$, then

$$
\int_{(c, d) \cap J} L^{\prime}(t) F(t) d t \geq-\frac{1}{4} \int_{(c, d) \cap J} L^{\prime}(t) d t
$$

Proof. We first note that $F(c)=-1 / 4=F(d), G(c)=-1 / 2=G(d)$.

$$
\begin{gathered}
F^{\prime}(t)=W^{\prime}(t)(\ln W(t)+2-2 W(t))=W^{\prime}(t) J(t) \\
G^{\prime}(t)=2 W^{\prime}(t)\left(-2(1-W(t) \ln (1-W(t))-W(t))=2 W^{\prime}(t) K(t)\right.
\end{gathered}
$$

where

$$
\begin{aligned}
J^{\prime}(t) & =W^{\prime}(t)\left(\frac{1}{W(t)}-2\right) \\
K^{\prime}(t) & =W^{\prime}(t)(2 \ln (1-W(t))+1)
\end{aligned}
$$

Since $W^{\prime}>0$ if and only if $c<d$, as $t$ increases along $(c, d) \cap J, F(t)$ decreases then increases while $G(t)$ increases then decreases which proves the first pair of results.

Let $L$ be ORD-equivalent to $W$. In this case, $W^{\prime}>0$ implies $L^{\prime}>0, c<d$ which implies

$$
\begin{aligned}
\int_{(c, d) \cap J} L^{\prime}(t) F(t) d t & \leq-\frac{1}{4} \int_{(c, d) \cap J} L^{\prime}(t) d t \\
\int_{(c, d) \cap J} L^{\prime}(t) G(t) d t & \geq-\frac{1}{2} \int_{(c, d) \cap J} L^{\prime}(t) d t
\end{aligned}
$$




\section{Budget-Constrained Sequential Auctions with Incomplete Information}

and $W^{\prime}<0$ implies $L^{\prime}<0, d<c$ which implies

$$
\begin{aligned}
\int_{(c, d) \cap J} L^{\prime}(t) F(t) d t & =-\int_{(d, c) \cap J} L^{\prime}(t) F(t) d t \leq \frac{1}{4} \int_{(d, c) \cap J} L^{\prime}(t) d t=-\frac{1}{4} \int_{(c, d) \cap J} L^{\prime}(t) d t \\
\int_{(c, d) \cap J} L^{\prime}(t) G(t) d t & =-\int_{(d, c) \cap J} L^{\prime}(t) G(t) d t \geq \frac{1}{2} \int_{(d, c) \cap J} L^{\prime}(t) d t=-\frac{1}{2} \int_{(c, d) \cap J} L^{\prime}(t) d t
\end{aligned}
$$

Let $L$ be ORDR-equivalent to $W$ and $W^{\prime}>0 . c<d$ and $L^{\prime}<0$ implies the last result.

Given any bidding function $B$ and its associated probability $\nabla(t)=1-\Delta(t)$, there is a monotonic cover of $B$. Denote by $J$ the union of intervals over which the cover is strictly monotonic and let $c=\nabla^{-1}(0), d=\nabla^{-1}(1)$ denote the end-points of $J$. Either the cover is strictly increasing over $J$ and $c<d$ or the cover is strictly decreasing over $J$ and $d<c$. Even though there may be gaps in $J$, by nature of a cover, the values of the bidding function form a continuous range as $t$ ranges over $J$. Below, the subscripts indicate the price rule.

Lemma 14 If the equilibrium bidding function under $1^{\text {st }}$ price rules is ORD-equivalent to that under $2^{\text {nd }}$ price rules, then

$$
B_{1}(t)=B_{2}(t)-\frac{\int_{(c, t) \cap J} B_{2}^{\prime}(t) \nabla(s) d s}{(\nabla(t))^{2}}
$$

Proof. Since $B_{1}$ and $B_{2}$ are ORD-equivalent there are ORD-equivalent monotonic covers of $B_{1}$ and $B_{2}$ with a common associated $J$ and $\nabla$. Since $\nabla(t)=1-\Delta(t)$, (4) implies

$$
\begin{aligned}
B_{2}^{\prime}(t)(1-\nabla(t))-2 B_{2}(t) \nabla^{\prime}(t) & =-\left(v_{1}(t)-v_{2}(t)\right) \nabla^{\prime}(t)+\delta^{\prime}(t) \\
B_{1}^{\prime}(t) \nabla(t)+2 B_{1}(t) \nabla^{\prime}(t) & =\left(v_{1}(t)-v_{2}(t)\right) \nabla^{\prime}(t)-\delta^{\prime}(t)
\end{aligned}
$$

so that

$$
\left(B_{1}^{\prime}(t)-B_{2}^{\prime}(t)\right) \nabla(t)+2\left(B_{1}(t)-B_{2}(t)\right) \nabla^{\prime}(t)=-B_{2}^{\prime}(t)
$$

which implies that, for $t \in J$,

$$
B_{1}(t)=B_{2}(t)-\frac{\int_{(c, t) \cap J} B_{2}^{\prime}(t) \nabla(s) d s}{(\nabla(t))^{2}}
$$

The next two Lemmas restrict to $1^{\text {st }}$ (denoted by $a=0$ ) and $2^{\text {nd }}$ price rules (denoted by $a=1)$. Let the subscripts on $B$ denote the order of sale.

Lemma 15 If $v_{a}-v_{\beta}+I, v_{\beta}-v_{\alpha}+I$ and $I$ are each ORD-equivalent to the equilibrium bidding function under order $\alpha, \beta$ and under order $\beta, \alpha$ then, for $t \in J$

$$
B_{\alpha, \beta}(t)+B_{\beta, \alpha}(t)=I(t)-a \frac{\int_{(d, t) \cap J}(1-\nabla(s))^{2} I^{\prime}(s) d s}{(1-\nabla(t))^{2}}-(1-a) \frac{\int_{(c, t) \cap J} \nabla^{2}(s) I^{\prime}(s) d s}{\nabla^{2}(t)}
$$




\section{Budget-Constrained Sequential Auctions with Incomplete Information}

Proof. Since $B_{\alpha, \beta}$ and $B_{\beta . \alpha}$ are ORD-equivalent, the associated $J$ and $\Delta$ are common. Since $\nabla(t)=1-\Delta(t)$, (4) and the fact that $I$ is ORD-equivalent to both bidding functions imply the next three equations

$$
\begin{gathered}
B_{\alpha, \beta}^{\prime}(t)(a(1-\nabla(t))-(1-a) \nabla(t))-2 B_{\alpha, \beta}(t) \nabla^{\prime}(t)=-\left(v_{\alpha}(t)-v_{\beta}(t)+I(t)\right) \nabla^{\prime}(t) \\
B_{\beta, \alpha}^{\prime}(t)(a(1-\nabla(t))-(1-a) \nabla(t))-2 B_{\beta, \alpha}(t) \nabla^{\prime}(t)=-\left(v_{\beta}(t)-v_{\alpha}(t)+I(t)\right) \nabla^{\prime}(t) \\
\left(B_{\alpha, \beta}^{\prime}(t)+B_{\beta, \alpha}^{\prime}(t)\right)(a(1-\nabla(t))-(1-a) \nabla(t))-2\left(B_{\alpha, \beta}(t)+B_{\beta, \alpha}(t)\right) \nabla^{\prime}(t)=-2 I(t) \nabla^{\prime}(t)
\end{gathered}
$$

Lemma 16 If $v_{a}-v_{\beta}+I$ is ORDR-equivalent to $v_{\beta}-v_{\alpha}+I$ and each bidding function is ORD-equivalent to its associated critical value $v(t)$ then, if $I(t)=I$

$$
B_{\alpha, \beta}(t)+B_{\beta, \alpha}(t)=I+\frac{\int_{(c, t) \cap J}\left(a B_{\alpha, \beta}^{\prime}(s)+(1-a) B_{\beta, \alpha}^{\prime}(s)\right) \nabla_{\alpha, \beta}(s) d s}{\nabla_{\alpha, \beta}^{2}(t)} \text { for } t \in J
$$

Proof. Since $\nabla(t)=1-\Delta(t),(4)$ implies that

$B_{\alpha, \beta}^{\prime}(t)\left(a\left(1-\nabla_{\alpha, \beta}(t)\right)-(1-a) \nabla_{\alpha, \beta}(t)\right)-2 B_{\alpha, \beta}(t) \nabla_{\alpha, \beta}^{\prime}(t)=-\left(v_{\alpha}(t)-v_{\beta}(t)+I\right) \nabla_{\alpha, \beta}^{\prime}(t)$ $B_{\beta, \alpha}^{\prime}(t)\left(a\left(1-\nabla_{\beta, \alpha}(t)\right)-(1-a) \nabla_{\beta, \alpha}(t)\right)-2 B_{\beta, \alpha}(t) \nabla_{\beta, \alpha}^{\prime}(t)=-\left(v_{\beta}(t)-v_{\alpha}(t)+I\right) \nabla_{\beta, \alpha}^{\prime}(t)$

By assumption, $\nabla_{\alpha, \beta}(t)+\nabla_{\beta, \alpha}(t)=1$ so that after adding the two equations, we obtain

$$
\begin{aligned}
& \left(a\left(B_{\alpha, \beta}^{\prime}(t)+B_{\beta, \alpha}^{\prime}(t)\right)+(1-a)\left(B_{\alpha, \beta}^{\prime}(t)+B_{\beta, \alpha}^{\prime}(t)\right)\right) \nabla_{\alpha, \beta}(t)+2\left(B_{\alpha, \beta}(t)+B_{\beta, \alpha}(t)\right) \nabla_{\alpha, \beta}^{\prime}(t) \\
= & 2 I \nabla_{\alpha, \beta}^{\prime}(t)+a B_{\alpha, \beta}^{\prime}(t)+(1-a) B_{\beta, \alpha}^{\prime}(t)
\end{aligned}
$$

which implies the result where $\nabla_{\alpha, \beta}(c)=0, \nabla_{\alpha, \beta}(d)=1, c, d \in J$ where $\nabla_{\alpha, \beta}$ is ORDequivalent to $B_{\alpha, \beta}$ on $J$ which is ORDR-equivalent to $B_{\beta, \alpha}$ on $J$.

Proof of Theorem 10: By assumption, there is a common $\nabla$ and $J$. Since the expected price of good 1 under $2^{\text {nd }}$ price rules is

$$
\exp p_{1}^{2}=2 \int_{(c, d) \cap J} B_{2}(t)\left(1-\nabla(t) \nabla^{\prime}(t) d t\right.
$$

and the expected price of good 1 under $1^{\text {st }}$ price rules is

$$
\exp p_{1}^{1}=2 \int_{(c, d) \cap J} B_{1}(t) \nabla(t) \nabla^{\prime}(t) d t
$$

the expected difference in the price of good 1 under $1^{\text {st }}$ and $2^{\text {nd }}$ price rules is

$$
\begin{aligned}
& \exp p_{1}^{1}-\exp p_{1}^{2} \\
= & 2 \int_{(c, d) \cap J} B_{1}(t) \nabla(t) \nabla^{\prime}(t) d t-2 \int_{(c, d) \cap J} B_{2}(t)\left(1-\nabla(t) \nabla^{\prime}(t) d t\right.
\end{aligned}
$$




\section{Budget-Constrained Sequential Auctions with Incomplete Information}

After using Lemma 14 and grouping terms we obtain that $\exp p_{1}^{1}-\exp p_{1}^{2}$ equals

$$
\int_{(c, d) \cap J} B_{2}(t) d \frac{(2 \nabla(t)-1)^{2}}{2}-2 \int_{(c, d) \cap J} \int_{(c, t) \cap J} B_{2}^{\prime}(s) \nabla(s) d s d \ln (\nabla(t))
$$

After integrating by parts (noting that $\nabla(c)=0, \nabla(d)=1$ ), we obtain $\exp p_{1}^{1}-\exp p_{1}^{2}$ equals

$$
2\left(\frac{B_{2}(d)}{4}-\frac{B_{2}(c)}{4}\right)+2 \int_{(c, d) \cap J} B_{2}^{\prime}(t)\left(\nabla(t) \ln \nabla(t)-\frac{(2 \nabla(t)-1)^{2}}{4}\right) d t
$$

By Lemma 13 using $\nabla(t)=W(t)$ is ORD-equivalent to $L=B_{2}$ we obtain

$$
\exp p_{1}^{1}-\exp p_{1}^{2} \leq 2\left(\frac{B_{2}(d)}{4}-\frac{B_{2}(c)}{4}\right)-\frac{2}{4} \int_{(c, d) \cap J} B_{2}^{\prime}(t) d t=0
$$

Proof of Theorem 11: If $v_{\alpha}-v_{\beta}+I, v_{\beta}-v_{\alpha}+I, I$, are ORD-equivalent to the equilibrium bidding functions $B_{\alpha, \beta}$ and $B_{\beta, \alpha}$ then the expected income of the bidder with the higher bid is independent of the sequence of sale so that the expected revenue is independent of the sequence of sale. Since the sum of the expected prices of the goods equals exp $\max \left\{I\left(t_{1}\right), I\left(t_{2}\right)\right\}$, the difference $\exp _{\alpha}^{\beta, \alpha}-\exp p_{\alpha}^{\alpha, \beta}$ in the expected price of good $\alpha$ under sequence $\beta, \alpha$ and the expected price under sequence $\alpha, \beta$ is

$$
\begin{aligned}
& 2 \int_{(c, d) \cap J} I(t) \nabla(t) \nabla^{\prime}(t) d t-2 a \int_{(c, d) \cap J}\left(B_{\beta, \alpha}(t)+B_{\alpha, \beta}(t)\right) \nabla^{\prime}(t)(1-\nabla(t)) d t \\
& -2(1-a) \int_{(c, d) \cap J}\left(B_{\beta, \alpha}(t)+B_{\alpha, \beta}(t)\right) \nabla^{\prime}(t) \nabla(t) d t
\end{aligned}
$$

After using Lemma 15 and grouping terms, we obtain that $\exp _{\alpha}^{\beta, \alpha}-\exp p_{\alpha}^{\alpha, \beta}$ equals

$$
\begin{aligned}
& a \int_{(c, d) \cap J} I(t) d\left(\frac{(2 \nabla(t)-1)^{2}}{2}\right)-2 a \int_{(c, d) \cap J}\left(\int_{(d, t) \cap J}(1-\nabla(s))^{2} I^{\prime}(s) d s\right) d(\ln (1-\nabla(t))) \\
& +2(1-a) \int_{(c, d) \cap J} \int_{(c, t) \cap J} \nabla^{2}(s) I^{\prime}(s) d s d(\ln \nabla(t))
\end{aligned}
$$

After integrating by parts (noting that $\nabla(c)=0, \nabla(d)=1$ ), we obtain that $\exp _{\alpha}^{\beta, \alpha}-\exp p_{\alpha}^{\alpha, \beta}$ equals

$$
\begin{aligned}
& a \frac{I(d)}{2}-a \frac{I(c)}{2}+a \int_{(c, d) \cap J} I^{\prime}(t)\left(2(\ln (1-\nabla(t)))(1-\nabla(t))^{2}-\frac{(2 \nabla(t)-1)^{2}}{2}\right) d t \\
& -2(1-a) \int_{(c, d) \cap J} \ln \nabla(t) \nabla^{2}(t) I^{\prime}(t) d t
\end{aligned}
$$




\section{Budget-Constrained Sequential Auctions with Incomplete Information}

By Lemma 13 using $\nabla=W, I=L$, we obtain that $\exp _{\alpha}^{\beta, \alpha}-\exp p_{\alpha}^{\alpha, \beta} \geq$

$$
\begin{aligned}
& a \frac{I(d)}{2}-a \frac{I(c)}{2}-\frac{a}{2} \int_{(c, d) \cap J} I^{\prime}(t) d s-2(1-a) \int_{(c, d) \cap J} \ln \nabla(t) \nabla^{2}(t) I^{\prime}(t) d t \\
= & -2(1-a) \int_{(c, d) \cap J} \ln \nabla(t) \nabla^{2}(t) I^{\prime}(t) d t \geq 0
\end{aligned}
$$

Proof of Theorem 12: WLOG, I focus on $\alpha$ and assume $B_{a, \beta}$ strictly increases on $J$. The expected price of good $\alpha$ under order $\beta, \alpha$ minus that under order $\alpha, \beta$ is

$$
\begin{aligned}
& \exp p_{\alpha}^{\beta, \alpha}-\exp p_{\alpha}^{\alpha, \beta} \\
= & I-2 a\left(\int_{(d, c) \cap J} B_{\beta, \alpha}(t)\left(1-\nabla_{\beta, \alpha}(t)\right) \nabla_{\beta, \alpha}^{\prime}(t) d t+\int_{(c, d) \cap J} B_{\alpha, \beta}(t)\left(1-\nabla_{\alpha, \beta}(t)\right) \nabla_{\alpha, \beta}^{\prime}(t) d t\right) \\
& -2(1-a)\left(\int_{(d, c) \cap J} B_{\beta, \alpha}(t) \nabla_{\beta, \alpha}(t) \nabla_{\beta, \alpha}^{\prime}(t) d t+\int_{(c, d) \cap J} B_{\alpha, \beta}(t) \nabla_{\alpha, \beta}(t) \nabla_{\alpha, \beta}^{\prime}(t) d t\right)
\end{aligned}
$$

After using Lemma $16, \nabla_{\alpha, \beta}(t)+\nabla_{\beta, \alpha}(t)=1, I(t)=I$ and grouping terms, we obtain that $\exp p_{\alpha}^{\beta, \alpha}-\exp p_{\alpha}^{\alpha, \beta}$ equals

$$
\begin{aligned}
2 & \left.a\left(\int_{(c, d) \cap J} B_{\alpha, \beta}(t) d\left(\frac{\left(2 \nabla_{\alpha, \beta}(t)-1\right)^{2}}{4}\right)-\int_{(c, d) \cap J} \int_{(c, t) \cap J} B_{\alpha, \beta}^{\prime}(s) \nabla_{\alpha, \beta}(s) d s d \ln \nabla_{\alpha, \beta}(t)\right)\right) \\
& \left.+2(1-a)\left(\int_{(c, d) \cap J} B_{\beta, \alpha}(t) d\left(\frac{\left(2 \nabla_{\alpha, \beta}(t)-1\right)^{2}}{4}\right)-\int_{(c, d) \cap J} \int_{(c, t) \cap J} B_{\beta, \alpha}^{\prime}(s) \nabla_{\alpha, \beta}(s) d s d \ln \nabla_{\alpha, \beta}(t)\right)\right)
\end{aligned}
$$

After integrating by parts (noting that $\nabla_{\alpha, \beta}(c)=0, \nabla_{\alpha, \beta}(d)=1$ ) we obtain that $\exp p_{\alpha}{ }^{\beta, \alpha}-$ $\exp p_{\alpha}^{\alpha, \beta}$ equals

$$
\begin{aligned}
& 2 a\left(\frac{B_{\alpha, \beta}(d)}{4}-\frac{B_{\alpha, \beta}(c)}{4}+\int_{(c, d) \cap J} B_{\alpha, \beta}^{\prime}(t)\left(\ln \nabla_{\alpha, \beta}(t) \nabla_{\alpha, \beta}(t)-\frac{\left(2 \nabla_{\alpha, \beta}(t)-1\right)^{2}}{4}\right) d t\right) \\
& +2(1-a)\left(\frac{B_{\beta, \alpha}(d)}{4}-\frac{B_{\beta, \alpha}(c)}{4}+\int_{(c, d) \cap J} B_{\beta, \alpha}^{\prime}(t)\left(\ln \nabla_{\alpha, \beta}(t) \nabla_{\alpha, \beta}(t)-\frac{\left(2 \nabla_{\alpha, \beta}(t)-1\right)^{2}}{4}\right) d t\right)
\end{aligned}
$$

By Lemma 13 , since $B_{\alpha, \beta}$ is ORD-equivalent to $\nabla_{\alpha, \beta}$ and $B_{\beta, \alpha}$ is ORDR-equivalent to $\nabla_{\alpha, \beta}$,

$$
\exp p_{\alpha}^{\beta, \alpha}-\exp p^{\alpha, \beta} \leq 2\left(\frac{B_{\alpha, \beta}(d)}{4}-\frac{B_{\alpha, \beta}(c)}{4}-\frac{1}{4} \int_{(c, d) \cap J} B_{\alpha, \beta}^{\prime}(t) d t\right)=0
$$

under $2^{\text {nd }}$ price rules $(a=1)$ and

$$
\exp p_{\alpha}^{\beta, \alpha}-\exp p^{\alpha, \beta} \geq 2\left(\frac{B_{\beta, \alpha}(d)}{4}-\frac{B_{\beta, \alpha}(c)}{4}-\frac{1}{4} \int_{(c, d) \cap J} B_{\beta, \alpha}^{\prime}(t) d t\right)=0
$$

under $1^{\text {st }}$ price rules $(a=0)$ which proves the result. 


\section{Budget-Constrained Sequential Auctions with Incomplete Information}

\section{References}

[1] Ashenfelter, O.(1989), "How Auctions Work for Wine and Art", JEP, 3(3), 23-26.

[2] Ashenfelter, O. and Genesove, D.(1992), "Testing for Price Anomalies in Real-Estate Auctions", AER, 80(2), 501-505

[3] Benoit, J.P. and Krishna, K. (2001), "Multiple-Object Auctions with Budget Constrained Bidders", REStud, 68, 155-179.

[4] Bernhardt, D. and Scoones, D.(1994), "A Note on Sequential Auctions", AER, 84, 653-657.

[5] Black and De Meza (1992), "Systematic Price Differences Between Successive Auctions are No Anomaly", JEMS, 1(4), 607-628.

[6] Bulow and Klemperer, P. (2002), "Prices and the Winner's Curse", Rand, 33(1), 1-21.

[7] Burguet, R.J. and McAfee, R.P. (2005), "License Prices for Financially Constrained Firms"

[8] Chatterjee, K. and Samuelson, W.(1983), "Bargaining Under Incomplete Information", OR, 31, 835-852.

[9] Che, Y.K. and Gale, I.(1998), "Standard Auctions with Financially-Constrained Buyers", RES, 65, 1-21.

[10] Clement, GL and Hopenhayn, H.(2002), "A Theory of Financing Constraints and Firm Dynamics", unpublished manuscript.

[11] Cramton, P. C.(1995), "Money Out of Thin Air: The Nationwide Narrowband PCS Auction" JEMS, 4, 267-343.

[12] Engelbrecht-Wiggans, R.(1987), "Optimal Constrained Bidding", IJGT, 16(2), 115-121.

[13] Engelbrecht-Wiggans, R. and Menezes, F.(1993), "Sequential Auctions with Continuation Costs", ANU WP \#225.

[14] Engelbrecht-Wiggans, R. and Weber, R. J.(1979), "An Example of a Multi-Object Auction game", $M S, 25(12), 1272-1277$.

[15] Fazzari, S. and Athey, M.J. (1987), "Asymmetric Information, Financing Constraints, and Investment", Review of Economics and Statistics, 69, 481-7

[16] Fazzari, S., Hubbard, R.G. and Petersen, B.C. (1988), "Financing constraints and Corpporate Investment", Brookings Papers on Economic Activity, No. 1, 141-206

[17] Fazzari, S., Petersen, B. (1993), Rand, "Working Capital and Fixed Investment: New Evidence on Financing Constraints", 24, 328-42

[18] Fudenberg, D. and Tirole, J.(1991), "Perfect Bayesian Equilibrium and Sequential Equilibrium", JET, 53, 236-260

[19] Gale, I. and Hausch, D.(1994), "Bottom Fishing and Declining Prices in Sequential Auctions", GEB, 7, 318-331. 


\section{Budget-Constrained Sequential Auctions with Incomplete Information}

[20] Gale, I. and Stegeman, M. (2001), "Sequential Auctions of Endogenously Valued Objects", GEB, 36, 74-103.

[21] Genesove, D.(1993), "Adverse Selection in the Wholesale Used Car Market", JPE, 101(4), 644-665.

[22] Harris, M. and Raviv, A.(1981), "Allocation Mechanisms and the Design of Auctions", Econometrica, 49, 1477-1499.

[23] Hart, O. and Moore, J.H. (1995), "Debt and Seniority: An Analysis of the Role of Hard Claims in Constraining Management, AER, 85, 567-85

[24] Hirsch, M.W. and Smale, S. (1974), "Differential Equations, Dynamical Systems, and Linear Algebra", Academic Press, New York.

[25] Hendricks, K., and Porter, R.H.(1992), "Joint Bidding in Federal OCS Auctions", AER, $82(2), 506-511$.

[26] Klemperer, P. (1999), "Auction Theory", Journal of Economic Surveys, 13(3), 227-286.

[27] Krishna, K. (1999), "Auctions with endogenous valuations: the snowball effect revisited", ET, 13, 377-391.

[28] Krishna, K.(1993), "Auctions with Endogenous Valuations and the Evolution of Markets", AER, 83, 147-160.

[29] Leininger, W., Linhart, P. and Radner, R.(1989), "The Sealed-Bid Mechanism for Bargaining with Incomplete Information", JET, 48, 63-106.

[30] Lewis, T. and Sappington, D. E. (1989a), "Inflexible Rules in Incentive Problems", AER, 79, 69-84

[31] Lewis, T. and Sappington, D. E. (1989b), "Countervailing Incentives in Agency Problems", JET, 49, 294-313

[32] Love, I. (2003), "Financial Development and Financing Constraint: New Evidence from the Structural Investment Model", Reveiw of Financial Studies, Fall, 765-791

[33] Maskin, E. and Riley, J.(1984), "Optimal Auctions with Risk Averse Buyers", Econometrica, 52, 1473-1518.

[34] McAfee, R. P.(1993), "Mechanism Design by Competing Sellers", Econometrica, 61(6), 1281-1312.

[35] McAfee, R. P. and McMillan, J.(1987), "Auctions and Bidding", JEL, 25, 699-738.

[36] McAfee, R. P. and Vincent, D.(1993), "The Declining Price Anomaly", JET, 191-212.

[37] Menezes, F.(1993), "Ascending-Price Multiple-Object Auctions", The Australian National University WP\# 254.

[38] Milgrom, P.(1987), "Auction Theory", Advances in Economic Theory, Truman Bewley, editor, Cambridge University Press.

[39] Milgrom, P, and Weber, R.(1982), "A Theory of Auctions and Competitive Bidding", Econometrica, 50, 1089-1122. 


\section{Budget-Constrained Sequential Auctions with Incomplete Information}

[40] Myerson, R.(1981), "Optimal Auction Design", MOR,6, 58-73.

[41] Myerson, R. and Satterthwaite, M.(1983), "Efficient Mechanisms for Bilateral Trading", JEL, 29, 265-281.

[42] Ortega-Reichert, A.(1968), "Models for Competitive Bidding Under Uncertainty", Department of Operations Research Technical Report Number 8, Stanford University.

[43] Palfrey, T. R.(1980), "Multiple-Object, Discriminatory Auctions with Bidding Constraints: A Game-Theoretic Analysis", MS, 26(9), 935-946.

[44] Peters, M. and Severinov, S.(1997), "Competition Between Sellers who Offer Auctions Instead of Prices", JET, , 1993, 141-179.

[45] Pitchik, C. and Schotter, A.(1986), "Budget-Constrained Sequential Auctions", NYU.

[46] Pitchik, C. and Schotter, A.(1988), "Perfect Equilibria in Budget-Constrained Sequential Auctions: An Experimental Study", The Rand Journal of Economics, 19, 363-388.

[47] Pitchik, C.(1989), "Budget Constrained Sequential Auctions with Incomplete Information", LSE WP TE 89201.

[48] Riley, J. and Samuelson, W.(1981), "Optimal Auctions", AER, 71, 381-392.

[49] Swinkels, J.(1989), "Multi-unit, Multi-period Auctions, the Efficiency of Symmetric Equilibria and Supply Uncertainty, manuscript.

[50] Weber, R.(1983), "Multiple-Object Auctions", Auctions, Bidding and Contracting: Uses and Theory, (R. E. Engelbrecht-Wiggans, M. Shubik and R. Stark, editors), New York University Press.

[51] Whited, T. (1992), "Debt, Liquidity Constraints, and Corporate Investment: Evidence from Panel Data", Journal of Finance, 47, 1425-60

[52] Wilson, R.(1984), "Trading Procedures", Mimeo, Stanford Business School. 